This document is the accepted manuscript version of the following article:

Zhang, K., Bach, P. M., Mathios, J., Dotto, C. B. S., \& Deletic, A. (2020). Quantifying the benefits of stormwater harvesting for pollution mitigation. Water Research, 171,115395 (12 pp.). https://doi .org/10.1016/j.watres.2019.115395

This manuscript version is made available under the CC-BY-NC-ND 4.0 1icense http://

creativecommons.org/1icenses/by-nc-nd/4.0/

\title{
1 Quantifying the benefits of stormwater harvesting for pollution mitigation
}

2

3

4

Kefeng Zhang ${ }^{1, *}$, Peter M. Bach ${ }^{2,3,4}$, John Mathios ${ }^{4,5}$, Cintia B. S. Dotto ${ }^{6}$, Ana Deletic ${ }^{1}$

${ }^{1}$ UNSW Water Research Centre, School of Civil and Environmental Engineering, UNSW Sydney, NSW 2052, Australia

${ }^{2}$ Swiss Federal Institute of Aquatic Science \& Technology (Eawag), Überlandstrasse 133, Dübendorf, Switzerland

${ }^{3}$ Institute of Environmental Engineering, ETH Zürich, 8093, Zürich, Switzerland

${ }^{4}$ Monash Infrastructure Research Institute, Department of Civil Engineering, Monash University, Clayton VIC 3800, Australia

${ }^{5}$ DPM Consulting PTY. LTD., 22 Business Park Drive, Notting Hill, VIC 3168 Australia

${ }^{6}$ City of Melbourne, VIC 3000 Australia

*Corresponding author email: kefeng.zhang860225@gmail.com

\section{Abstract}

Stormwater harvesting (SWH) provides multiple benefits to urban water management. Other than providing water for human use, it also reduces the volume of polluted stormwater discharge to the environment. There are currently no methods available to quantify the additional environmental benefits, which could encourage greater uptake of the practice. This paper investigates a number of factors (climate and catchment characteristics, pollutant reduction targets, etc.) that could impact upon the benefits of SWH for pollution reduction through sensitivity analyses. A method was developed and tested for quantification of the pollution mitigation benefits by SWH under different scenarios. A novel indicator, Impervious Area Offset (IAO), was proposed to reflect the additional impervious area that can be left untreated to achieve the equivalent pollution load reduction targets due to the introduction of SWH. Results indicate significant correlations $(p<0.01)$ between IAO values and extraction rate (proportion of total annual runoff removed due to the harvesting system and water use substitution), system type, and pollutant reduction targets. The proposed linear empirical relationships between IAO values and extraction rate for different types of system configurations and pollution reduction targets were well represented by observed linear regression (average $R^{2}=0.98$ for all tested scenarios). Empirical relationships were validated successfully against different scenarios, with differences between predicted IAO and baseline IAO values being only $\pm 4.5 \%$ for the majority of the validation scenarios. Using this simple and reliable method to rapidly quantify SWH benefits can further add to the growing business case of adopting SWH practices. 
Keywords: pollution loads; catchment imperviousness; water sensitive urban design (WSUD); low impact development; sponge city.

\section{Introduction}

Due to rapid urbanisation, stormwater has become the major contributor to the deterioration of water quality in urban environments (Jeng et al., 2005). In response, various solutions have been developed known as Water Sensitive Urban Design (WSUD) in Australia, Low Impact Development (LID) in the USA, and Nature Based Solutions (NBS) in Europe, among its many other common names (Fletcher et al., 2015) and, more recently, as Sponge Cities in China (Jun et al., 2017). Typical WSUD systems, e.g., stormwater bioretention systems and constructed wetlands, are usually effective in removing various types of pollutants in stormwater (Hatt et al., 2009;Malaviya and Singh, 2012;Zhang et al., 2015), and regulation has prescribed mandatory treatment requirements to reduce pollutant levels in stormwater (VSC, 1999). Indeed, current WSUD assets are predominantly implemented to meet environmental water quantity or quality targets (i.e., the main driver for these systems). Nevertheless, their additional multiple benefits are acknowledged, e.g., frequent flood mitigation (Zhang et al., 2019), waterway health protection (Fletcher et al., 2007), microclimate improvement (Wong et al., 2013), and improvement of amenity values in urban landscapes (Polyakov et al., 2015).

Stormwater is also regarded as a valuable water resource that can be harvested for non-potable uses, e.g., irrigation, car washing, and toilet flushing (Hatt et al., 2006;Campisano et al., 2017). The multiple benefits of stormwater harvesting (SWH) have also been reported (Mitchell et al., 2007;Campisano et al., 2017), e.g., supplementing water supply, which is an important driver for SWH, especially in water-stressed cities (Fisher-Jeffes L. et al., 2017). Hammes et al. (2018) estimated that, by having a $45 \mathrm{~m}^{3}$ stormwater tank at a university technology centre (a total $5500 \mathrm{~m}^{2}$ stormwater collection area) to receive filtered stormwater from porous asphalt pavements, potable water savings of up to $54 \%$ was achievable if the harvested stormwater were reused to flush toilets 
semiarid regions in the U.S. Additionally, by harvesting stormwater, flows can be attenuated and restored to closer to pre-development hydrology (Ashbolt et al., 2012;Anim et al., 2019), which has significant ecological merits.

WSUD often plays a vital role in both stormwater pollution management and SWH, which are closely linked. However, for the purposes of design and planning in practice, they are often viewed as mutually exclusive and non-interacting objectives, which is counterintuitive to the principles of Integrated Urban Water Management (IUWM) (Mitchell, 2004). Often, urban developers tend to overlook the benefits of SWH for several reasons. On the one hand, they are perceived by asset managers (local councils and water authorities) to have increased maintenance due to the additional WSUD infrastructure required for SWH (e.g., storage tanks) (Campisano et al., 2017;Kuller et al., 2018b). Furthermore, the aesthetic inferiority of SWH infrastructure impedes the uptake of SWH (i.e., low public acceptance), unless WSUD systems such as wetlands are used for storage, which, in fact, are used only in 5\% of all SWH cases, according to Hatt et al. (2006). Most importantly, although it is widely acknowledged that extracting treated water from storage systems for reuse can further protect downstream water quality (Anderson, 2003;Fletcher et al., 2007), this benefit is not easily quantified and there is currently no method available (unlike water quantity benefits that can be readily assessed with storage-behaviour and rainfall-runoff modelling, e.g., Mitchell et al. (2001)), and thus the business case is not easily justified (Kuller et al., 2018a). Hence, for simplicity, SWH is often assumed to provide no benefit to water quality other than the initial treatment required by guidelines, which in many cases matches current prescribed best management practices for stormwater quality control. Overall, these aspects impede the willingness to pay for such infrastructure.

As such, although these impediments to implementing SWH appear daunting, the benefits of SWH should not simply be ignored; instead, they deserve a more meticulous investigation. Development of methodologies and algorithms to rapidly quantify these benefits, particularly for pollution mitigation (which has been driving the uptake of WSUD over the past decades) is necessary. Knowledge of these benefits would facilitate improved planning and design of these systems, including: 
(1) leveraging additional treatment capacity of existing treatment and harvesting systems in the event of increased urbanisation, thereby offsetting the need for new WSUD infrastructure,

(2) decreasing the surface area requirement of WSUD assets through the provision of SWH within the system (a benefit to both the urban developer and the asset manager),

(3) leveraging potential overtreatment to benefit existing downstream urban developments, which are space constrained (and most challenging for WSUD implementation from the developers' perspective), and

(4) facilitating greater return on investment and general savings in infrastructure cost to both the developer and the asset manager (generally local councils) due to potential cost-sharing opportunities between multiple stakeholders (e.g., between utilities providers and the local council).

The first two quantifiable benefits are similar, with the second one less applicable to cases that already have WSUD implemented (i.e., it does not make sense to reduce the size/or remove the already existing systems). The two latter benefits can be estimated if we can better understand the first two benefits. As such, our focus in this paper will be on understanding the extent to which the addition of SWH to typical WSUD systems can provide additional treatment capacity. We hypothesise that this benefit can be expressed in terms of the additional impervious area it services (i.e., treats the runoff from) as a result of SWH, which in this paper we refer to as a new term - Impervious Area Offset (IAO).

In order to develop a method for quantification of IAO, we must understand the impact of a range of factors on SWH in both pollution reduction aspects (e.g., WSUD treatment performance) and harvesting aspects (e.g., supply volume and demand pattern). Designing any WSUD systems is directly related to the targets of pollution reduction, and usually stricter targets correspond to larger systems (Zhang et al., 2019). Furthermore, WSUD systems vary in pollution removal performance, e.g., it is usually easier to remove total suspend solids (TSS) than nutrients (Hatt et al., 2009; Malaviya and Singh, 2012). Hence, investigating the effect of different pollutant types may reveal varying benefits of SWH. Similarly, WSUD technology type also matters, e.g., stormwater biofilters are often 
more effective in removing pollution (Davis, 2007), but they may not have the storage capacity that constructed wetlands or ponds have. Various studies also show that system design parameters (e.g., filter depth, submerged zone depth, and detention time) significantly affect treatment performance (Hatt et al., 2006;Afrooz and Boehm, 2017). In terms of harvesting, the yield (or, in our case, the volume extracted from the catchment), demand pattern of harvested water, and the requirements of supply can certainly influence the benefits of SWH. Additionally, in a broader context, climatic conditions (e.g., rainfalls) and catchment size (which determine the scale of SWH cases), whose impacts on WSUD are often studied (Bach et al., 2013;Zhang et al., 2019), also need to be considered.

To the authors' knowledge, there is no clear understanding to what extend SWH is beneficial for pollution mitigation and what are the most significant factors that impact the benefits. Furthermore, there is also no published method to quantify these benefits. Hence, in this paper, we introduce a useful quantitative indicator - the Impervious Area Offset (IAO) to describe the benefits of SWH on pollution reduction. IAO reflects the additional impervious area that can be left untreated to achieve same pollution reduction targets due to SWH. A simple approach was developed for the first time to quantify the IAO values under various scenarios through exploratory modelling exercises (which also contributed to a deeper understanding of the most important factors). Specifically, we focus on the following objectives:

- testing the sensitivity of pollution reduction benefits in relation to various factors that influence SWH,

- developing and validating empirical relationships between SWH and pollution reduction benefits, and

- discussing the tangible implications of these established relationships for practice.

We hypothesise that, due to the scalability of such decentralised systems, climate and catchment properties may be less sensitive to SWH benefits, while other factors, including harvesting aspects (e.g., supply reliability, extraction volume) and pollutant reduction aspects (e.g., treatment target, pollutant type, and system designs), are sensitive to SWH benefits. We showed that having an 
empirical model is crucial to quantifying the real benefit of SWH, which can be used to estimate the tangible cost-benefit of SWH for different stakeholders and improve its business case or general viability, and encourage the uptake of the practice.

\section{Material \& Methods}

In this section, we first propose an approach to quantify SWH benefits by calculating Impervious Area Offset, IAO (defined as the additional impervious area that can be serviced by the WSUD due to SWH) using the Model for Urban Stormwater Improvement Conceptualisation (MUSIC, by eWater, 2014) (Section 2.1). Over a hundred different scenarios were set-up to test the sensitivities of various climate, system design, and SWH variables to IAO (section 2.2). Based on the sensitivity testing, empirical relationships between IAO and the most sensitive parameters were proposed, with detailed calibration and validation methodologies introduced in Section 2.3.

\subsection{Description of the quantitative approach}

\subsubsection{Selection of treatment and harvesting technologies}

There are a multitude of WSUD technologies for stormwater treatment and harvesting, each with a variety of planning, design, and implementation considerations. Stormwater biofilters and constructed wetlands and ponds, which are currently the most widely used WSUD systems for stormwater treatment and harvesting (Hatt et al., 2006), are the major focus of this study. Biofilters, known as rain gardens or bioretention systems, are often used for runoff reduction and pollution management and are highly scalable (Davis et al., 2009;Afrooz and Boehm, 2017). Constructed wetlands and ponds, typically in moderate to larger scales, can provide benefits in flood mitigation and pollution reduction (Al-Rubaei et al., 2016), as well as SWH (Mitchell et al., 2006). Additionally, this study also looks into the treatment train approach, which is often the practice of SWH (Wong et al., 2013), with the inclusion of vegetated swales (often used to provide flow collection, attenuation, and pretreatment, Leroy et al., 2016), and rainwater tanks (stormwater retention and fit-for-purpose water supply, Burns et al., 2015). These technologies are currently the most widely used across Australia, as evidenced in several case studies in the literature (Hatt et al., 2006; Mitchell et al., 2006). 


\subsubsection{Basic model setup}

In this study, MUSIC, which is the state-of-the-art WSUD modelling tool in the Australian urban water industry, was used to evaluate the treatment and harvesting performance of different WSUD systems and treatment trains (eWater, 2014). The rainfall-runoff simulation in MUSIC is based on the model developed by Chiew and McMahon (1997). Runoff can be routed using either simple translation only or the Muskingum-Cunge method (Cunge, 1969). Within WSUD systems, hydrologic routing is simulated using the modified Puls Method (Ball et al., 2016), and water quality treatment employs first-order exponential decay over the length of the treatment systems and a series of continuously stirred tank reactors. The water storage tank modelling is based on a simple filling and spilling storage behaviour model with extraction from the tank according to constant or seasonal water demand pattern. A detailed description of MUSIC can be found in its user manual (eWater, 2014). To some extend MUSIC has been tested and validated against monitored data on a series of treatment measures (Wong et al., 2002). Imteaz et al. (2013) also tested the accuracy of MUSIC in predicting flow conditions and removal efficiencies by stormwater treatment systems and found that MUSIC can simulate flow conditions with good accuracy but had varying performance of pollutant removal efficiencies prediction.

As with many other stormwater management models, e.g., SWMM (Rossman, 2017) or SOURCE (Carr and Podger, 2012), MUSIC also has limitations, e.g., it requires calibration and validation for a specific case study, as well as full uncertainty analyses. Nevertheless, apart from the fact that it is widely used in Australia, MUSIC was selected in this study as it enables long-term continuous simulations (with fine temporal resolution) and its water quality and WSUD treatment modules are more extensive than other similar models (Elliott and Trowsdale, 2007). It should be noted, however, that the same approach can be used by other models (preferably calibrated and validated for a local case study) to investigate the significance of relationships between $\mathrm{SWH}$ and pollution mitigation and develop the approach of quantifying the SWH benefits.

Figure 1 illustrates a schematic setup of the MUSIC model (based on a node-and-link-based user interface) to assess the pollution reduction benefits of SWH based on a typical treatment train 
191

192

193

194

195

196

197

198

199

200

201

202

203

204

205

206

207

208

209

210

211

212

scenario. Briefly, runoff from a fully impervious catchment node (Urban catchment) drains into Treatment systems (in this case, swale and biofilter, which are coupled in series and designed to meet specific pollution reduction targets). Treated effluent from the treatment system is harvested in a storage tank (Harvesting System). The tank is set up to supply a specific water demand at a predefined volumetric reliability. The amount of water demand is adjusted (using Equation 1) such that the total guaranteed supply volume (defined by the system's volumetric reliability - see Equation 2) corresponds to a specific proportion of the harvested water (e.g., $25 \%, 50 \%, 75 \%$, and 100\%). The ratio of volume supplied to total runoff volume of the catchment is termed the extraction rate (percentage of water removed from the catchment for non-potable end uses). For example, if the tank receives a total inflow of $1000 \mathrm{~m}^{3}$, the required demand volume to guarantee an extraction rate of $25 \%$ for a tank that is $100 \%$ reliable would be $250 \mathrm{~m}^{3}$. For a tank that is $80 \%$ reliable, however, the required demand for the same extraction rate would be $312.5 \mathrm{~m}^{3}$ (i.e., requesting more demand, but only receiving $80 \%$ of it). The equivalent annual demand for a given extraction rate and target reliability is given by Equation 1.

$$
\mathrm{V}_{\text {demand }}=\frac{\mathrm{V}_{\text {in }} \times \mathrm{p}_{\mathrm{ext}}}{\mathrm{R}_{\mathrm{v}} / 100 \%}
$$

Equation 1

where:

$$
V_{\text {demand }}-\text { total annual demand }\left(m^{3} / y r\right)
$$

$V_{\text {in }}-$ total annual tank inflow $\left(\mathrm{m}^{3} / y r\right)$

$P_{\text {ext }}-$ extraction rate (\%), percentage of water removed from the catchment for end uses

$R_{v}$ - volumetric reliability of the system (\%), defined as:

$$
\mathrm{R}_{\mathrm{v}}=\frac{\sum \mathrm{V}_{\text {supplied }}}{\sum \mathrm{V}_{\text {demand }}} \times 100 \%
$$

Equation 2

$V_{\text {supplied }}$ - volume supplied by the harvesting system $\left[\mathrm{m}^{3}\right]$

Overflow from the treatment system is not directed into the storage tank, but is instead bypassed to the final downstream point. This is important as good practice dictates that only treated effluent 
The pollution reduction benefit is quantified in terms of the how much untreated impervious area could be offset downstream such that targets were still complied with: the aforementioned impervious area offset (IAO). Taking the SWH scenario shown in Figure 1 as an example, the Treatment systems (swale + biofilter) are designed to remove $45 \%$ of $\mathrm{TN}$ for the Urban catchment at the Final downstream point without considering the harvesting component; the Harvesting system (i.e., tank) in the same catchment removes additional runoff via harvesting water for reuse and thus results in greater than $45 \% \mathrm{TN}$ loads at the Final downstream point. This means that $\mathrm{x} \%$ of additional impervious area in the Extra catchment can be left untreated such that the TN reduction at the Final downstream point is still measured at $45 \%$ and therefore complies with treatment targets. The IAO is then defined as the ratio of x\% of additional impervious area of the Extra catchment divided by the total impervious area of the Urban catchment.

\subsection{Scenarios for sensitivity testing}

As discussed, SWH is influenced by various aspects, and all these variables are summarised in Table

1. Due to the large number of possible combinations that we could test in Table 1 , we undertook sensitivity testing in two stages. In Stage 1, parameters, which were hypothesised to be least influential, including climate characteristics, catchment properties, and recycling patterns were first investigated based on the biofilter only and set to a constant value if their sensitivity was low or negligible. A total of 21 sensitivity scenarios were investigated. In Stage 2, two separate data sets were created to look into the sensitivity of extraction rate, pollutant type, reduction target and system design (Table 1):

- "target-based" data set, using fixed design parameters, with which we explored variable pollution reduction targets for three individual technology types, three pollutants of varying targets, and four different extraction rates - a total of 108 sensitivity scenarios; 
- "design-based" data set, using a fixed pollution management target, with which we explored variable system designs for the three different technology types, with two contrasted design configurations and, additionally, two coupled designs, known as 'treatment trains', three pollutants (with the same management target), and four different extraction rates - a total of 96 sensitivity scenarios.

The results generated from sensitivity testing were plotted to illustrate the relationships between the IAO and the variables, accompanied by statistical analysis of the correlations using simple Pearson correlation and multiple regression.

Table 1. Summary of variables tested and their selected values

\begin{tabular}{|c|c|c|}
\hline Category & Variables & Selected Values \\
\hline Climate & $\begin{array}{l}\text { City } \\
\text { Rainfall Length (years) }\end{array}$ & $\begin{array}{l}\text { Melbourne, Brisbane, Perth } \\
1 \text { year }(1959), 10 \text { years }(2000-2009)\end{array}$ \\
\hline Catchment & $\begin{array}{l}\text { Area [ha] } \\
\text { Imperviousness [\%] }\end{array}$ & $\begin{array}{l}1 \text { ha, } 10 \text { ha, } 100 \text { ha } \\
100 \%\end{array}$ \\
\hline Harvesting & $\begin{array}{l}\text { Reliability of Supply [\%] } \\
\text { Demand Pattern } \\
\text { Extraction rate [\% of inflow] }\end{array}$ & $\begin{array}{l}60 \%, 80 \%, 90 \% \\
\text { Constant, Seasonal (scaled by Potential evapotranspiration) } \\
25 \%, 50 \%, 75 \%, 100 \%\end{array}$ \\
\hline Treatment & $\begin{array}{l}\text { Pollutant Type } \\
\text { Reduction Target }[\%]^{2)} \\
\text { System Type } \\
\text { System Design Configuration }\end{array}$ & $\begin{array}{l}\text { Total Suspend Solids (TSS), Total Nitrogen (TN), Total Phosphorus (TP) } \\
\text { TSS 95\%, 85\%, 60\% } \\
\text { TP } \quad 60 \%, 45 \%, 20 \% \\
\text { TN } 55 \%, 45 \%, 20 \% \\
\text { Biofilter, Wetland, Pond } \\
\text { Different designs for each system }{ }^{3)} \text { : } \\
\text { - } \quad \text { Biofilter A: extended detention depth (EDD) of } 100 \mathrm{~mm} \text {, filter } \\
\quad \text { media depth (FD) of } 500 \mathrm{~mm} \\
\text { - } \quad \text { Biofilter B: EDD - } 500 \mathrm{~mm} \text {, FD -300 mm } \\
\text { - } \quad \text { Biofilter C: EDD - } 300 \mathrm{~mm} \text {, FD -500 mm } \\
\text { - } \quad \text { Wetland A: EDD - } 750 \mathrm{~mm} \text {, detention time } 72 \mathrm{hr} \\
\text { - } \quad \text { Wetland C: EDD - } 300 \mathrm{~mm} \text {, detention time } 48 \mathrm{hr} \\
\text { - } \quad \text { Pond A: EDD - } 1000 \mathrm{~mm} \text {, detention time } 72 \mathrm{hr} \\
\text { - } \quad \text { Pond B: EDD - } 2000 \mathrm{~mm} \text {, detention time } 72 \mathrm{hr} \\
\text { - } \quad \text { Pond C: EDD - } 3000 \mathrm{~mm} \text {, detention time } 24 \mathrm{hr} \\
\text { Treatment trains include (first two used for sensitive testing scenarios and } \\
\text { the rest for validation scenarios): } \\
\text { TT_1: wetland A+ storage tank } \\
\text { TT_2: vegetated swales + biofilter A+ storage tank } \\
\text { TT_V1_A: sedimentation pond + biofilter A + storage tank } \\
\text { TT_V1_C: sedimentation pond + biofilter C + storage tank } \\
\text { TT_V2_A: wetland A + pond storage } \\
\text { TT_V2_C: wetland C + pond storage }\end{array}$ \\
\hline
\end{tabular}
rainfall series were used: 1-year rainfall data from Year 1959 (a typical year representing long term average in these cities), and 10-year rainfall between 2000 and 2009 (which had long term drought period; all 6-minute timestep). Refer to the supplementary document for the details and statistics of different climate types. ${ }^{2}$ BPEM guideline (VSC, 1999) requires load reduction of $85 \%$ for TSS, $45 \%$ for TP and 45\% for TN, and the selected 
targets in this study had a good coverage of what is required. ${ }^{3)}$ Details of the all the designs are given in Table S1-Table S3 of the Supplementary document. Both design A and B were used in the sensitivity testing of "design-based" data set, while only design A was used in the sensitivity testing of Stage 1, Stage 2 "targetbased" data set, and the treatment train scenarios. Design C was only used in the empirical relationship validation scenarios introduced below.

\subsection{Development and validation of empirical relationships for assessing IAO}

\subsubsection{Proposed empirical relationship}

Having found significant correlation between IAO and variables from sensitivity testing, we proposed and tested an empirical relationship. As will become clear in the results, due to significant linear relationships observed between IAO and extraction rates $\left(p_{\text {ext }}\right)$ for different types of pollutants, reduction targets, and system types, we proposed the following linear relationship:

$$
\mathrm{IAO}=\mathrm{f}\left(\mathrm{p}_{\text {ext }}\right)=\mathrm{m} \times\left(\mathrm{p}_{\text {ext }}-\mathrm{b}_{\text {thresh }}\right) \quad \text { Equation } 3
$$

where:

$\boldsymbol{I A O}$ - the impervious area offset attained through harvesting (\%), i.e., the percentage of additional impervious area (based on catchment area being treated), which can be left untreated such that pollution targets are still met due to harvesting.

$\boldsymbol{m}$ - the slope of the linear regression between $p_{e x t}$ and IAO; we refer to this as the benefit coefficient.

$\boldsymbol{b}_{\text {thresh }}$ - the benefit threshold, i.e., the minimum extraction required for an IAO to be noticeable.

It should be noted that this study did not intend to develop universal relationships that are globally transferable, but rather to understand what factors may be necessary to consider (in this case, $p_{\text {ext }}$ and other factors that impact the $m$ and $b_{\text {thresh }}$ ) if such relationships are to be developed elsewhere. Therefore, the findings of this study can guide planners or water managers in developing their own case-specific relationships, or if they simply assess IAO for a particular catchment, to understand how this IAO may be affected by different system types, pollutant types and harvesting requirements. Nevertheless, the relationships developed in this study can be used for the studied cities or other with similar conditions for rapidly quantification of the SWH benefits (i.e., IAO). 


\subsubsection{Parameter estimation}

279 Equation 3 was used to fit the acquired relationships between the IAO and the variables from sensitivity testing results to estimate $m$ and $b_{\text {thresh }}$ values. The goodness-of-fit $\left(\mathrm{R}^{2}\right)$ was estimated, and t-tests were conducted to check whether there was a statistical difference between baseline IAO (from our quantitative approach using MUSIC) and modelled IAO (from the proposed linear empirical relationship). The estimated $m$ and $b_{\text {thresh }}$ values were then summarised as look-up values for model validation/prediction.

\subsubsection{Validation of the empirical relationships}

In order to validate the empirical relationship, different and new hypothetical SWH scenarios were set up and simulated in MUSIC, which included three individual systems (biofilter, wetland, and pond) as well as treatment trains. Each individual system has two designs: Design A and Design C (see Table 1). New treatment trains that differed from those that were tested in sensitivity testings were also used: TT_V1_A (sedimentation pond + biofilter A + storage tank), TT_V1_C (sedimentation pond + biofilter $\mathrm{C}+$ storage tank), TT_V2_A (wetland A + pond storage) and TT_V2_C (wetland C + pond storage).

A total of 45 scenarios with different treatment targets and extraction rates were generated in MUSIC to model the IAO values (as the 'Baseline IAO'). The empirical relationship was used to calculate the IAO value (as the 'Modelled IAO') for each scenario using the $m$ and $b_{\text {tresh }}$ values estimated from the sensitivity testings and validated against the 'Baseline IAO' values. For the treatment target and extraction rate that were different from sensitivity testings, linear interpolation was performed to derive $m$ values since system designs were insensitive to IAO and significant linear correlation between treatment target and extraction rate to IAO values were exhibited. As Design C was not used in sensitivity testing but solely for validation, the values for Design A were taken. For treatment trains scenarios, parameters corresponding to the dominant treatment system type were used, e.g., biofilter for TT_V1 and wetland for TT_V2.

\section{Results and Discussion}




\subsubsection{Impact of climate type and catchment and recycling demand on IAO}

Table 2 summarises results from Stage 1 sensitivity testing, indicating the impact of climate characteristics, catchment properties, and recycling requirements on IAO. We found that climate conditions were less influential to IAO values, which were estimated to be around $1.0 \pm 0.5 \%$ for all the three climate types (Table 2a). Furthermore, the difference in IAO between modelling results for 1-yr and 10-yr climate data was small, with a slightly lower IAO corresponding to the shorter period.

Similarly, catchment size ( 1 ha to 100 ha) was also found to have minimal impact on IAO, with differences of $<0.3 \%$ observed when different pollutant targets were set (Table $2 b$ ). However, initial sensitivity testing showed that pollutant type had considerable influence on the IAO, with the highest benefit achieved when TP was selected as the target pollutant (i.e., IAO $\approx 66.7 \%$ ), followed by TN (i.e., $\mathrm{IAO} \approx 29.0 \%$ ) and TSS (i.e., $\mathrm{IAO} \approx 1.0 \%$ ).

Table 2: Impact of variables on Impervious Area Offset (IAO) - results from Stage 1 sensitivity testing

\begin{tabular}{|c|c|c|c|c|c|c|}
\hline City & $\begin{array}{l}\text { Climate } \\
\text { length }\end{array}$ & $\begin{array}{c}\text { Impervious } \\
\text { area [ha] }\end{array}$ & $\begin{array}{c}\text { Supply } \\
\text { reliability [\%] }\end{array}$ & $\begin{array}{l}\text { Reduction } \\
\text { target [\%] }\end{array}$ & $\begin{array}{c}\text { Reuse } \\
\text { pattern }\end{array}$ & $\begin{array}{l}\text { Impervious Area } \\
\text { Offset (IAO) [\%] }\end{array}$ \\
\hline \multicolumn{7}{|c|}{ (a) Impact of climate variability } \\
\hline \multirow{2}{*}{ Brisbane } & $1 \mathrm{yr}$ & \multirow{6}{*}{10} & \multirow{6}{*}{80} & \multirow{6}{*}{ TSS 85} & \multirow{6}{*}{ Constant } & $0.48 \%$ \\
\hline & $10 \mathrm{yrs}$ & & & & & $1.22 \%$ \\
\hline \multirow{2}{*}{ Perth } & $1 \mathrm{yr}$ & & & & & $0.92 \%$ \\
\hline & $10 \mathrm{yrs}$ & & & & & $1.00 \%$ \\
\hline \multirow{2}{*}{ Melbourne } & $1 \mathrm{yr}$ & & & & & $0.93 \%$ \\
\hline & $10 \mathrm{yrs}$ & & & & & $1.1 \%$ \\
\hline \multicolumn{7}{|c|}{ (b) Impact of catchment size } \\
\hline \multirow{9}{*}{ Melbourne } & \multirow{9}{*}{$10 \mathrm{yrs}$} & 1 & \multirow{9}{*}{80} & \multirow{3}{*}{ TSS 85} & \multirow{9}{*}{ Constant } & $0.9 \%$ \\
\hline & & 10 & & & & $1.01 \%$ \\
\hline & & 100 & & & & $1.03 \%$ \\
\hline & & 1 & & \multirow{3}{*}{ TP 60} & & $66.7 \%$ \\
\hline & & 10 & & & & $66.7 \%$ \\
\hline & & 100 & & & & $66.7 \%$ \\
\hline & & 1 & & \multirow{3}{*}{$\mathrm{TN} 45$} & & $28.9 \%$ \\
\hline & & 10 & & & & $28.9 \%$ \\
\hline & & 100 & & & & $29.2 \%$ \\
\hline \multicolumn{7}{|c|}{ (c) Impact of demand pattern and supply reliability } \\
\hline \multirow{6}{*}{ Melbourne } & \multirow{6}{*}{$10 \mathrm{yrs}$} & \multirow{6}{*}{10} & \multirow{4}{*}{60} & \multirow{6}{*}{ TSS 85} & Constant & $0.94 \%$ \\
\hline & & & & & Seasonal & $0.93 \%$ \\
\hline & & & & & Constant & $0.93 \%$ \\
\hline & & & & & Seasonal & $1.00 \%$ \\
\hline & & & \multirow{2}{*}{90} & & Constant & $0.93 \%$ \\
\hline & & & & & Seasonal & $1.10 \%$ \\
\hline
\end{tabular}


Reliability and demand pattern were also less sensitive to the results (Table 2c), i.e., IAO values were always $\sim 1.0 \pm 0.07 \%$ for different patterns and reliability requirements. It was expected that demand patterns would not be sensitive since our evaluation is based on annual statistics and demands may not necessarily be met by the system. As such, reliability, which is directly related to extracted volume (set by $V_{\text {demand }}$ from Equation 1 based on extraction rate $p_{\text {ext }}$ ) is therefore believed to be a more direct indication of water removed from the system, and hence it needs to be included in further analysis.

Overall, these initial sensitivity tests support our hypothesis that climate type and catchment characteristics, recycling pattern, and reliability were least influential to SWH benefits. Hence, they were kept constant in further sensitivity analyses. Specifically, a catchment with an area of 1 ha (i.e., $10,000 \mathrm{~m}^{2}$ ) at Melbourne with a 10-yr climate series were selected, and the harvesting reliability was set as $80 \%$ at a constant demand pattern. These preliminary results also indicated that pollutant type was sensitive to the IAO, and its sensitivity is more thoroughly investigated in the next section.

\subsubsection{Impact of extraction rate, pollutant type, system type, and reduction targets on IAO}

Figure 2 illustrates the relationships between IAO and extraction rates for different pollutant types and treatment targets, with their statistical correlations also presented. Significant, positive and linear correlations between the extraction rate and IAO are observed $(\mathrm{R}=0.35 ; p<0.01$, Figure 2$)$. This was expected since the larger the volume of water supplied (i.e., higher extraction rate), the more benefits (i.e., higher IAO) can be gained through SWH. Although the strength of correlation is only low to medium (i.e., $0.3<\mathrm{R}<0.5$ ), this was based on all different scenarios, and for a specific system design and pollution reduction target, the linear relationship is very strong (as shown in Figure 2).

Figure 2 Relationship between extraction rates and IAO for different system type, pollutant, and reduction targets: results from the "target-based" data set.

Applying SWH to treatment systems that specifically target different pollutants also exhibits variable levels of benefits. This observation is also extended to different system types and designs (Figure 2), e.g., for ponds and wetlands, the average values of IAO achieved from SWH were found to be TN $(73.5 \%)>\mathrm{TP}(25.0 \%)>\mathrm{TSS}(5.59 \%)$, while for biofilters the order was $\mathrm{TP}(31.1 \%)>\mathrm{TN}(16.9 \%)>$ 
TSS $(0.42 \%)$. These differences were attributed to the varying performance of these systems in removing pollutants. TN is usually more difficult to remove than TSS and TP by wetlands and ponds because of its highly soluble nature and because it is strongly influenced by variable operational conditions (Fletcher, 2004;Malaviya and Singh, 2012). TN removal in biofilters, however, can be improved through the inclusion of submerged zones, which can create anaerobic conditions that promote the denitrification process as per Zhang et al. (2011). Indeed, the treatment performance design curves generated for the tested systems (refer to Figure S1-S3 of the supplementary document) in this study revealed that the critical design pollutant for wetlands and ponds was TN, while that for biofilters was TP. Hence, stormwater harvesting would be most beneficial for additional TN removal in wetlands and ponds, and TP removal for biofilters.

System type also has significant impact on the harvesting benefits $(\mathrm{R}=0.30 ; p<0.01$, Figure 2$)$, ponds have the highest average IAO values $\left(=42.9 \%\right.$, i.e., if we had $10,000 \mathrm{~m}^{2}$ catchment with SWH using a pond, connecting an extra $4290 \mathrm{~m}^{2}$ catchment to the system would still comply with pollutant reduction targets), followed by wetland (average 26.4\%) and biofilters (average 16.1\%) across different target pollutants. Among these treatment systems, ponds are least effective in removing pollutants, with sedimentation being the main mechanisms to trap pollutants of coarse to medium sizes (Fletcher, 2004), while biofilters are most effective (Davis, 2007;Hatt et al., 2009). Additionally, wetlands and ponds are usually large systems and often have storage capacities of their own, hence they are regarded as more suitable for SWH systems (Hatt et al., 2006). Therefore, to achieve the same treatment targets, ponds and wetlands are preferable to biofilters for the additional SWH benefits. However, system costs and available space should also be considered in practice as ponds and wetlands usually occupy significantly more space than biofilters for achieving the same treatment targets.

Pollutant reduction targets are negatively correlated to IAO values for TSS and TN in all systems ( $p<0.01$, Figure 2), e.g., with a target to remove $60 \%$ TSS by ponds, the IAO value is estimated to be $11 \%$, which is more than four times of the IAO when targeting 95\% TSS removal (i.e., IAO=2.5\%) at the same extraction rate of $50 \%$. Indeed, lower treatment means higher levels of pollutant in the 
treated water, which, if harvested for reuse, can lead to greater benefits. Results indicate that for a catchment with lower requirements of treatment on TSS and TN, SWH will lead to greater pollution mitigation benefits. TP, however, was once again an exception for biofilters. As they are the most effective treatment measure (Davis, 2007; Hatt et al., 2009), their design sizes are extremely sensitive to the reduction targets of the critical pollutant, e.g., it is estimated that a biofilter system removing $60 \%$ of TP needs to be sized to $4.2 \%$ of the catchment impervious area, which is over 50 times larger than the system that treats $20 \%$ TP (i.e., only $0.08 \%$ of impervious area - Figure S1 of the supplementary document). Such a significant increase in system size due to the treatment requirement would allow significantly more water to be treated and stored in tanks for harvesting (consequently resulting in greater benefits). Nevertheless, it is not practical and cost-effective to design the biofilter for very high TP removal, and instead, a variety of WSUD systems could be selected (to form a treatment train) to meet the targets.

Figure 3 further confirms the linear and significant correlation $(\mathrm{p}<0.01)$ between extraction rates and IAO according to the analysis of the 'design-based' data set. Similarly, the relationships again vary according to different pollutant type, and pollutant reduction targets $(\mathrm{p}<0.01)$. Specifically, Figure 3 shows that for varying designs, clear differences were found, e.g., with a target to remove $45 \% \mathrm{TN}$, the IAO value was $30 \%$ for Wetland B and $45 \%$ for Wetland A at the same extraction rate of $75 \%$. However, statistical analysis indicates that the system designs and IAO values are not significantly correlated $(p>0.05)$. Additionally, the SWH benefits achieved using treatment trains are mainly due to the predominant treatment systems. In $T T_{-} 1$, for example, which uses a wetland as the treatment system and pond as storage (i.e., minimal further improvements), similar benefits were modelled as those for the individual wetland scenario (i.e., Wetland A).

Results from the multiple regression analysis further confirmed that the IAO could be predicted from the variables including extraction rate, pollutant type, system type and reduction targets, i.e., $\mathrm{R}^{2}=0.90$ for the 'target-based' data set and $\mathrm{R}^{2}=0.96$ for the 'design-based' data set. 


\subsection{Testing and validation of empirical relationship}

401

\subsubsection{Estimation of empirical model parameters}

402 The linear correlation lines between the IAO and extraction rate shown in Figure 2 and Figure 3 were

403 fitted to Equation 3 for estimation of benefit coefficient $(m)$ and benefit threshold $\left(b_{\text {thresh }}\right)$ values for 404 different pollutants and systems types, thereby generating the look-up table of their values presented in Table 3. As shown, the fit of the IAO empirical relationships to the linear regression lines was

406 generally good (average $\mathrm{R}^{2}=0.98$ ). Comparison of the estimated IAO (from MUSIC) and the modelled 407 IAO also showed no statistical difference (evidenced by high $p$ values from t-tests), with the 408 maximum different observed for Biofilter A targeting $95 \%$ of TSS $\left(\Delta \mathrm{IAO}_{\max }=2.5 \%\right.$ and $\Delta \mathrm{IAO}_{\text {avg } \pm s t d}=$ $4090.14+0.70 \%)$. Hence, these results show that the proposed linear empirical relationships appear to be a 410 good representation of the actual correlations between IAO and the most sensitive parameters.

411 Table 3 Performance of the proposed empirical relationship: fitted parameter ( $m$ and $b_{\text {thresh }}$ ) values

412 estimated and modelled IAO values from the sensitivity testing

\begin{tabular}{|c|c|c|c|c|c|c|c|c|c|}
\hline System & Pollutant & Target & $\begin{array}{l}\text { Modelled } \\
\text { IAO [\%] } \\
\end{array}$ & $\mathbf{m}$ & $\mathbf{b}_{\text {thresh }}$ & $\mathbf{R}^{2}$ & $\begin{array}{l}\text { Estimated } \\
\text { IAO [\%] }\end{array}$ & $\begin{array}{l}p \text { value } \\
(t \text { test })\end{array}$ & $\triangle I A O^{l}$ \\
\hline \multirow{9}{*}{ Biofilter A } & TSS & 95 & $0.0 \%$ & 0.025 & 0.507 & 0.956 & $2.5 \%$ & 0.208 & $2.50 \%$ \\
\hline & TSS & 85 & $1.0 \%$ & 0.009 & 0.246 & 0.663 & $0.9 \%$ & 0.484 & $-0.10 \%$ \\
\hline & TSS & 60 & $0.7 \%$ & 0.006 & 0.160 & 0.892 & $0.6 \%$ & 0.380 & $-0.10 \%$ \\
\hline & $\mathrm{TP}$ & 60 & $61.2 \%$ & 0.616 & -0.020 & 0.996 & $61.6 \%$ & 0.877 & $0.40 \%$ \\
\hline & $\mathrm{TP}$ & 45 & $56.3 \%$ & 0.566 & -0.015 & 0.999 & $56.6 \%$ & 0.929 & $0.30 \%$ \\
\hline & $\mathrm{TP}$ & 20 & $27.0 \%$ & 0.269 & -0.017 & 0.999 & $26.9 \%$ & 0.920 & $-0.10 \%$ \\
\hline & TN & 55 & $25.0 \%$ & 0.257 & -0.014 & 0.994 & $25.7 \%$ & 0.933 & $0.70 \%$ \\
\hline & $\mathrm{TN}$ & 45 & $27.7 \%$ & 0.276 & 0.004 & 0.998 & $27.6 \%$ & 0.980 & $-0.10 \%$ \\
\hline & $\mathrm{TN}$ & 20 & $26.8 \%$ & 0.267 & 0.000 & 0.997 & $26.7 \%$ & 0.999 & $-0.10 \%$ \\
\hline \multirow[t]{3}{*}{ Biofilter B } & TSS & 85 & $1.8 \%$ & 0.018 & 0.175 & 0.894 & $1.8 \%$ & 0.332 & $0.00 \%$ \\
\hline & $\mathrm{TP}$ & 45 & $56.3 \%$ & 0.570 & -0.006 & 0.995 & $57.0 \%$ & 0.970 & $0.70 \%$ \\
\hline & $\mathrm{TN}$ & 45 & $27.7 \%$ & 0.280 & -0.004 & 0.994 & $28.0 \%$ & 0.982 & $0.30 \%$ \\
\hline \multirow[t]{9}{*}{ Wetland A } & TSS & 95 & $3.2 \%$ & 0.032 & 0.000 & 0.999 & $3.2 \%$ & 1.000 & $0.00 \%$ \\
\hline & TSS & 85 & $4.3 \%$ & 0.043 & 0.014 & 0.998 & $4.3 \%$ & 0.957 & $0.00 \%$ \\
\hline & TSS & 60 & $6.1 \%$ & 0.060 & -0.010 & 0.999 & $6.0 \%$ & 0.969 & $-0.10 \%$ \\
\hline & $\mathrm{TP}$ & 60 & $21.8 \%$ & 0.218 & 0.006 & 1.000 & $21.8 \%$ & 0.983 & $0.00 \%$ \\
\hline & $\mathrm{TP}$ & 45 & $25.0 \%$ & 0.254 & -0.003 & 0.997 & $25.4 \%$ & 0.990 & $0.40 \%$ \\
\hline & $\mathrm{TP}$ & 20 & $31.7 \%$ & 0.308 & -0.040 & 0.993 & $30.8 \%$ & 0.876 & $-0.90 \%$ \\
\hline & $\mathrm{TN}$ & 55 & $72.4 \%$ & 0.720 & 0.002 & 1.000 & $72.0 \%$ & 0.995 & $-0.40 \%$ \\
\hline & $\mathrm{TN}$ & 45 & $89.2 \%$ & 0.893 & 0.002 & 1.000 & $89.3 \%$ & 0.992 & $0.10 \%$ \\
\hline & $\mathrm{TN}$ & 20 & $127.1 \%$ & 1.267 & 0.003 & 1.000 & $126.7 \%$ & 0.992 & $-0.40 \%$ \\
\hline Wetland B & TSS & 85 & $3.1 \%$ & 0.031 & 0.006 & 0.999 & $3.1 \%$ & 0.980 & $0.00 \%$ \\
\hline
\end{tabular}




\begin{tabular}{|c|c|c|c|c|c|c|c|c|c|}
\hline & TP & 45 & $19.6 \%$ & 0.196 & 0.000 & 1.000 & $19.6 \%$ & 1.000 & $0.00 \%$ \\
\hline & $\mathrm{TN}$ & 45 & $59.6 \%$ & 0.597 & 0.009 & 1.000 & $59.7 \%$ & 0.971 & $0.10 \%$ \\
\hline \multirow[t]{9}{*}{ Pond A } & TSS & 95 & $5.3 \%$ & 0.053 & 0.004 & 1.000 & $5.3 \%$ & 0.988 & $0.00 \%$ \\
\hline & TSS & 85 & $15.0 \%$ & 0.152 & 0.022 & 0.998 & $15.2 \%$ & 0.931 & $0.20 \%$ \\
\hline & TSS & 60 & $22.7 \%$ & 0.232 & 0.014 & 0.998 & $23.2 \%$ & 0.957 & $0.50 \%$ \\
\hline & $\mathrm{TP}$ & 60 & $48.5 \%$ & 0.490 & 0.011 & 0.999 & $49.0 \%$ & 0.966 & $0.50 \%$ \\
\hline & $\mathrm{TP}$ & 45 & $55.0 \%$ & 0.557 & 0.009 & 0.999 & $55.7 \%$ & 0.973 & $0.70 \%$ \\
\hline & $\mathrm{TP}$ & 20 & $55.5 \%$ & 0.553 & -0.010 & 0.999 & $55.3 \%$ & 0.968 & $-0.20 \%$ \\
\hline & $\mathrm{TN}$ & 55 & $80.3 \%$ & 0.804 & 0.015 & 0.999 & $80.4 \%$ & 0.955 & $0.10 \%$ \\
\hline & $\mathrm{TN}$ & 45 & $117.5 \%$ & 1.181 & 0.020 & 0.998 & $118.1 \%$ & 0.939 & $0.60 \%$ \\
\hline & $\mathrm{TN}$ & 20 & $232.0 \%$ & 2.340 & 0.013 & 0.999 & $234.0 \%$ & 0.960 & $2.00 \%$ \\
\hline \multirow[t]{3}{*}{ Pond B } & TSS & 85 & $1.7 \%$ & 0.017 & 0.034 & 0.995 & $1.7 \%$ & 0.897 & $0.00 \%$ \\
\hline & $\mathrm{TP}$ & 45 & $79.5 \%$ & 0.809 & 0.018 & 0.998 & $80.9 \%$ & 0.943 & $1.40 \%$ \\
\hline & $\mathrm{TN}$ & 45 & $121.8 \%$ & 1.219 & 0.015 & 0.999 & $121.9 \%$ & 0.952 & $0.10 \%$ \\
\hline \multirow{3}{*}{$\begin{array}{l}\text { TT_1 } \\
\text { (Wetland A + } \\
\text { Storage tank) }\end{array}$} & TSS & 85 & $4.3 \%$ & 0.042 & -0.082 & 0.974 & $4.2 \%$ & 0.754 & $-0.10 \%$ \\
\hline & $\mathrm{TP}$ & 45 & $24.9 \%$ & 0.240 & -0.080 & 0.975 & $24.0 \%$ & 0.758 & $-0.90 \%$ \\
\hline & TN & 45 & $82.2 \%$ & 0.805 & -0.054 & 0.988 & $80.5 \%$ & 0.834 & $-1.70 \%$ \\
\hline \multirow{3}{*}{$\begin{array}{l}\text { TT_2 } \\
\text { (Vegetated swales } \\
+ \text { Biofilter A } \\
+ \text { Storage tank) }\end{array}$} & TSS & 85 & $1.0 \%$ & 0.010 & 0.096 & 0.955 & $1.0 \%$ & 0.714 & $0.00 \%$ \\
\hline & $\mathrm{TP}$ & 45 & $40.4 \%$ & 0.396 & -0.055 & 0.987 & $39.6 \%$ & 0.830 & $-0.80 \%$ \\
\hline & $\mathrm{TN}$ & 45 & $26.8 \%$ & 0.270 & 0.004 & 1.000 & $27.0 \%$ & 0.989 & $0.20 \%$ \\
\hline
\end{tabular}

The estimated benefit coefficient $(m)$ values indicate similar findings as observed in Figure 2 and

Figure 3. For example, $m$ varies according to the type of target pollutants and the systems, with $m_{T N}>m_{T P}>m_{T S S}$ for wetlands and ponds and $m_{T P}>m_{T N}>m_{T S S}$ for biofilters. Often, lower reduction targets also correspond to higher $m$ values (indicating more SWH benefits). Also, $m$ values for ponds (average 0.70) are usually higher than those of wetlands (average 0.38), followed by biofilters (average 0.26). Different $m$ values were found for two designs of each system. The differences, however, were not significant, especially for the biofilter system (Table 3). Similarly, the $m$ values estimated for the treatment train scenario were close to those of the dominant treatment system (e.g., TT_1 versus Wetland A), indicating its significant impact on SWH benefits.

Theoretically, the benefit threshold $\left(b_{\text {thresh }}\right)$ is generally taken as zeros for biofilters, ponds, and wetland, because any minimum extraction from the systems (i.e., $p_{\text {ext }} \geq 0$ ) leads to noticeable benefits 426 (i.e., IAO values $\geq 0$ ) according to Equation 3. This was confirmed by the very low values of 427 estimated $b_{\text {thresh }}(=0.002 \pm 0.041$, Table 3$)$, except for using Biofilter A targeting TSS removal, which is likely due to the low IAO values (thus small $m$ and relatively higher $b_{\text {thresh }}$ values calculated). Although not tested in this study, for rain tanks, the $b_{\text {thresh }}$ value is not zero if it is used as the only WSUD system for both stormwater treatment and harvesting (e.g., household rainwater tank). This is because rain tanks are not intrinsically designed to remove pollutants, unlike the other three systems. 
432 As such, benefits are only perceived after a certain amount of extraction where pollution removal is

433 achieved partly through sedimentation in the tank and direct removal of water from the system. This is

434 the main reason why we recommend keeping the $b_{\text {thresh }}$ term in the empirical equation, such that it can

435 capture this kind of behaviour and is therefore applicable to all types of WSUD systems.

\subsubsection{Validation of the Empirical relationship}

437 Figure 4 presents the comparison between baseline IAO and modelled IAO values for the 45 various

438 hypothetical scenarios with different system types and pollutant targets, with details of each scenario

439 summarised in Table 4. The worst estimation was found for Biofilter $\mathrm{C}$ targeting TP reductions with

440 estimated $\triangle \mathrm{IAO}$ (=Baseline-Modelled) values of $16.8-25.9 \%$, showing an underestimation of the

441 stormwater harvesting benefits by the empirical relationship, i.e., it is a conservative method of

442 estimating the SWH benefits. Overall, the proposed relationship predicted very close IAO values to

443 the baseline IAO values, with the range of $\triangle \mathrm{IAO}$ of between $-3.80 \%$ (overestimation) and $4.20 \%$

444 (underestimation) and $\Delta \mathrm{IAO}_{\text {avg } \pm s t d}=0.00 \pm 1.83 \%$. These results show that the proposed empirical

445 relationships are transferable to different SWH cases for estimation of their benefits in pollution

446 management.

447 Table 4 Summary of the validation results

\begin{tabular}{|c|c|c|c|c|c|c|c|c|}
\hline Scenarios & Pollutant & Target & $P_{e x t}$ & $\begin{array}{c}m \\
\text { value }^{1)}\end{array}$ & $\mathbf{b}_{\text {tresh }}{ }^{2)}$ & $\begin{array}{l}\text { Baseline } \\
\text { IAO [\%] }\end{array}$ & $\begin{array}{l}\text { Modelled } \\
\text { IAO [\%] }\end{array}$ & $\begin{array}{c}\Delta \text { IAO }(\text { Baseline - } \\
\text { modelled })\end{array}$ \\
\hline \multirow[t]{3}{*}{ Biofilter A } & TSS & 85 & 0.85 & 0.009 & 0.40 & $0.4 \%$ & $0.8 \%$ & $-0.4 \%$ \\
\hline & $\mathrm{TP}$ & 45 & 0.65 & 0.566 & 0.00 & $40.0 \%$ & $36.8 \%$ & $3.2 \%$ \\
\hline & TN & 45 & 0.55 & 0.276 & 0.00 & $13.0 \%$ & $15.2 \%$ & $-2.2 \%$ \\
\hline \multirow[t]{3}{*}{ Biofilter C } & TSS & 85 & 0.85 & 0.009 & 0.40 & $0.7 \%$ & $0.8 \%$ & $-0.1 \%$ \\
\hline & TP & 45 & 0.65 & 0.566 & 0.00 & $55.0 \%$ & $36.8 \%$ & $18.2 \%$ \\
\hline & TN & 45 & 0.55 & 0.276 & 0.00 & $16.5 \%$ & $15.2 \%$ & $1.3 \%$ \\
\hline \multirow[t]{3}{*}{ Biofilter C } & TSS & $70^{3)}$ & 0.85 & 0.007 & 0.00 & $0.3 \%$ & $0.6 \%$ & $-0.3 \%$ \\
\hline & TP & 30 & 0.65 & 0.388 & 0.00 & $51.1 \%$ & $25.2 \%$ & $25.9 \%$ \\
\hline & TN & 30 & 0.55 & 0.271 & 0.00 & $15.9 \%$ & $14.9 \%$ & $1.0 \%$ \\
\hline \multirow[t]{3}{*}{ Wetland A } & TSS & 85 & 0.85 & 0.043 & 0.00 & $3.7 \%$ & $3.7 \%$ & $0.0 \%$ \\
\hline & TP & 45 & 0.65 & 0.254 & 0.00 & $17.4 \%$ & $16.5 \%$ & $0.9 \%$ \\
\hline & $\mathrm{TN}$ & 45 & 0.55 & 0.893 & 0.00 & $50.2 \%$ & $49.1 \%$ & $1.1 \%$ \\
\hline \multirow[t]{3}{*}{ Wetland C } & TSS & 85 & 0.85 & 0.043 & 0.00 & $3.6 \%$ & $3.7 \%$ & $-0.1 \%$ \\
\hline & TP & 45 & 0.65 & 0.254 & 0.00 & $17.1 \%$ & $16.5 \%$ & $0.6 \%$ \\
\hline & TN & 45 & 0.55 & 0.893 & 0.00 & $48.9 \%$ & $49.1 \%$ & $-0.2 \%$ \\
\hline \multirow{3}{*}{ Wetland C } & TSS & 70 & 0.85 & 0.053 & 0.00 & $3.0 \%$ & $4.5 \%$ & $-1.5 \%$ \\
\hline & TP & 30 & 0.65 & 0.287 & 0.00 & $16.5 \%$ & $18.7 \%$ & $-2.2 \%$ \\
\hline & TN & 30 & 0.55 & 1.118 & 0.00 & $60.1 \%$ & $61.5 \%$ & $-1.4 \%$ \\
\hline \multirow[t]{3}{*}{ Pond A } & TSS & 85 & 0.85 & 0.152 & 0.00 & $13.0 \%$ & $12.9 \%$ & $0.1 \%$ \\
\hline & TP & 45 & 0.65 & 0.557 & 0.00 & $37.4 \%$ & $36.2 \%$ & $1.2 \%$ \\
\hline & $\mathrm{TN}$ & 45 & 0.55 & 1.181 & 0.00 & $62.2 \%$ & $65.0 \%$ & $-2.8 \%$ \\
\hline Pond C & TSS & 85 & 0.85 & 0.152 & 0.00 & $12.2 \%$ & $12.9 \%$ & $-0.7 \%$ \\
\hline
\end{tabular}




\begin{tabular}{|c|c|c|c|c|c|c|c|c|}
\hline & TP & 45 & 0.65 & 0.557 & 0.00 & $38.9 \%$ & $36.2 \%$ & $2.7 \%$ \\
\hline & TN & 45 & 0.55 & 1.181 & 0.00 & $61.2 \%$ & $65.0 \%$ & $-3.8 \%$ \\
\hline \multirow[t]{3}{*}{ Pond C } & TSS & "'70" & 0.85 & 0.200 & 0.00 & $16.0 \%$ & $17.0 \%$ & $-1.0 \%$ \\
\hline & TP & 30 & 0.65 & 0.555 & 0.00 & $34.4 \%$ & $36.1 \%$ & $-1.7 \%$ \\
\hline & TN & 30 & 0.55 & 1.876 & 0.00 & $99.6 \%$ & $103.2 \%$ & $-3.6 \%$ \\
\hline \multirow{3}{*}{$\begin{array}{l}\left.\text { TT_V1_A }{ }^{3}\right) \\
\text { (Sed. Pond + Biofilter } \\
\text { A + storage tank) }\end{array}$} & TSS & 85 & 0.85 & 0.009 & 0.00 & $0.3 \%$ & $0.4 \%$ & $-0.5 \%$ \\
\hline & TP & 45 & 0.65 & 0.566 & 0.00 & $40.1 \%$ & $36.8 \%$ & $3.3 \%$ \\
\hline & TN & 45 & 0.55 & 0.276 & 0.00 & $12.2 \%$ & $15.2 \%$ & $-3.0 \%$ \\
\hline \multirow{3}{*}{$\begin{array}{l}\text { TT_V1_C (Sed. Pond } \\
+ \text { Biofilter C + storage } \\
\text { tank) }\end{array}$} & TSS & 85 & 0.85 & 0.009 & 0.00 & $0.3 \%$ & $0.4 \%$ & $-0.5 \%$ \\
\hline & TP & 45 & 0.65 & 0.566 & 0.00 & $41.0 \%$ & $36.8 \%$ & $4.2 \%$ \\
\hline & TN & 45 & 0.55 & 0.276 & 0.00 & $14.7 \%$ & $15.2 \%$ & $-0.5 \%$ \\
\hline \multirow{3}{*}{$\begin{array}{l}\text { TT_V1_C } \\
\text { (Sed. Pond + Biofilter } \\
\text { C + storage tank) }\end{array}$} & TSS & 70 & 0.85 & 0.007 & 0.00 & $0.5 \%$ & $0.4 \%$ & $0.1 \%$ \\
\hline & TP & 30 & 0.65 & 0.389 & 0.00 & $42.1 \%$ & $25.3 \%$ & $16.8 \%$ \\
\hline & TN & 30 & 0.55 & 0.271 & 0.00 & $16.0 \%$ & $14.9 \%$ & $1.1 \%$ \\
\hline \multirow{3}{*}{$\begin{array}{l}\text { TT_V2_A } \\
\text { (Wetland A + Pond } \\
\text { Storage) }\end{array}$} & $\mathrm{TSS}$ & 85 & 0.85 & 0.152 & 0.00 & $12.5 \%$ & $12.9 \%$ & $-0.4 \%$ \\
\hline & TP & 45 & 0.65 & 0.557 & 0.00 & $35.7 \%$ & $36.2 \%$ & $-0.5 \%$ \\
\hline & TN & 45 & 0.55 & 1.181 & 0.00 & $63.1 \%$ & $65.0 \%$ & $-1.9 \%$ \\
\hline \multirow{3}{*}{$\begin{array}{l}\text { TT_V2_C } \\
\text { (Wetland C + Pond } \\
\text { Storage) }\end{array}$} & TSS & 85 & 0.85 & 0.152 & 0.00 & $12.9 \%$ & $12.9 \%$ & $0.0 \%$ \\
\hline & $\mathrm{TP}$ & 45 & 0.65 & 0.557 & 0.00 & $36.6 \%$ & $36.2 \%$ & $0.4 \%$ \\
\hline & TN & 45 & 0.55 & 1.181 & 0.00 & $67.1 \%$ & $65.0 \%$ & $2.1 \%$ \\
\hline \multirow{3}{*}{$\begin{array}{l}\text { TT_V2_C } \\
\text { (Wetland C + Pond } \\
\text { Storage) }\end{array}$} & TSS & 70 & 0.85 & 0.152 & 0.00 & $12.8 \%$ & $12.9 \%$ & $-0.1 \%$ \\
\hline & TP & 30 & 0.65 & 0.557 & 0.00 & $37.4 \%$ & $36.2 \%$ & $1.2 \%$ \\
\hline & TN & 30 & 0.55 & 1.181 & 0.00 & $68.3 \%$ & $65.0 \%$ & $3.3 \%$ \\
\hline \multicolumn{9}{|c|}{$\begin{array}{l}\text { 1) } m \text { values are looked up from Table } 3 \text { with the correspondence pollutant type and target. For systems with different design configurations } \\
\text { (e.g., configuration C) from Table } 3 \text {, the values for configuration A were taken as approximate as system design was found to be less } \\
\text { sensitive. For the pollutant target that was not covered from sensitivity estimations, simple linear interpolations were conducted to } \\
\text { derive } m \text { values. } \\
{ }^{2)} b_{\text {tresh }} \text { values were set to zeros as according to the discussion in the last section (the main treatment systems are biofilters and wetlands). } \\
{ }^{3)} \text { Sedimentation pond was only used for reducing TSS concentrations to } 50 \mathrm{mg} / \mathrm{L} \text {. }\end{array}$} \\
\hline
\end{tabular}

Figure 4 Results of validation of empirical relationships - baseline against modelled IAO values.

type of pollutants, and (b) different types of systems.

\subsection{Implications for practice}

This study shows that the SWH benefits (i.e., IAO in this case) can be reliably quantified using a simple linear empirical equation based on extraction rate for different types of systems and reduction targets. For example, given a fully impervious catchment of $10,000 \mathrm{~m}^{2}$, the required size of Biofilter A in Melbourne to achieve a $45 \%$ TP reduction is $72.0 \mathrm{~m}^{2}$ (refer to design curve of Biofilter A in supplementary document) when SWH is not accounted for. With an extraction rate of 0.65 from the storage tank receiving treated stormwater (e.g., using the TT_V1_A scenario), the modelled IAO is $36.8 \%$ (Table 4). This indicates that an additional impervious area of $3680 \mathrm{~m}^{2}$ can be left untreated or connected directly to the system while still meeting the treatment target (i.e., $45 \%$ TP reduction). In

467 Melbourne this means that a small neighbourhood of approximately 15 allotments (average lot size is $240 \mathrm{~m} 2$, Melbourne Water, 2010) can be offset. Without this harvesting scenario, this additional 
impervious surface may need $26.5 \mathrm{~m}^{2}$ of additional system surface area to ensure that a $45 \% \mathrm{TP}$ reduction can be achieved. Alternatively, in the original $10,000 \mathrm{~m}^{2}$ catchment, only approximately $45.5 \mathrm{~m}^{2}$ of biofilter A is needed instead of $72.0 \mathrm{~m}^{2}$, to achieve the same $45 \%$ TP reduction if the same level of extraction is maintained. These thought experiments highlight the usefulness of such a relationship for investigating cost-benefit implications (e.g., by coupling the empirical relationship with existing life cycle cost analysis tools), tackling on-site space constraints, and even leveraging the multi-functionality of WSUD infrastructure.

In this study, the extraction rates, system types and treatment targets were found to have significant correlations to IAO. However, although the other variables, e.g., climate conditions and catchment characteristics, were not highly correlated to IAO, they cannot be simply ignored in the bigger picture in the design of WSUD systems, as well as the aspects of SWH. For example, Zhang et al. (2019) found that larger WSUD systems are recommended to account for the future climate variability to meet the same treatment targets and also to achieve same reliability of SWH. In addition, different catchment characteristics, such as land use that are not tested in this study, may lead to different levels of pollutions. This may consequently lead to different system designs (and even system types due to the availability of space for WSUD) and SWH requirements (e.g., extraction rates under same harvesting reliability), thus impacting the SWH benefits.

WSUD planning is often undertaken based on water management targets (e.g., pollution reduction, volume reduction, harvesting) (Deletic et al., 2018), and/or other multiple objectives, such as cost (Xu et al., 2017) and carbon sequestration (Moore and Hunt, 2013). These different factors are always accounted for independently in the planning of WSUD, creating some levels of redundancy for its implementation (especially for pollution reduction). With the developed empirical relationships, integrated planning of WSUD based on these two important aspects could be more effective in creating financial incentives for local government and developers in adopting and harnessing the multiple benefits of WSUD infrastructures. Further research could be undertaken to integrate all those benefits to enhance business cases of SWH through WSUD practices.

\section{Conclusion}


In this study, we demonstrated for the first time that SWH has clear benefits in pollution reduction and an approach was developed to quantify these benefits. The IAO, our indicator of choice, reflects the additional impervious area that can be left untreated to achieve same pollution reduction targets due to SWH. A series of sensitivity analyses were conducted to explore the most important factors that impact IAO, and subsequently, SWH benefits. The results were used to develop and validate the empirical relationships to estimate IAO using the key independent variables. The main findings are: comparison would be interesting for future research.

\section{Acknowledgements}

519 This study was supported by the Australian Research Council Linkage Project titled "Advancing water pollution emissions modelling in cities of the future" (LP160100241). The authors would also like to thank Dr Meredith Morse for her English proof reading.

\section{References}


Afrooz, N., A. R. M. and Boehm, A.B., 2017. Effects of submerged zone, media aging, and antecedent dry period on the performance of biochar-amended biofilters in removing fecal indicators and nutrients from natural stormwater. Ecological Engineering 102, 320-330. Al-Rubaei, A.M., Engström, M., Viklander, M. and Blecken, G.-T., 2016. Long-term hydraulic and treatment performance of a 19-year old constructed stormwater wetlandFinally maturated or in need of maintenance? Ecological Engineering 95, 73-82.

Anderson, J., 2003. The environmental benefits of water recycling and reuse. Water Science and Technology: Water Supply 3(4), 1.

Anim, D.O., Fletcher, T.D., Pasternack, G.B., Vietz, G.J., Duncan, H.P. and Burns, M.J., 2019. Can catchment-scale urban stormwater management measures benefit the stream hydraulic environment? Journal of Environmental Management 233, 1-11.

Ashbolt, S., Aryal, S., Petrone, K., McIntosh, B.S., Maheepala, S., Chowdhury, R. and Gardner, T., 2012. Can stormwater harvesting restore pre-development flows in urban catchments in South East Queensland? Water science and technology 67(2), 446.

Bach, P.M., Deletic, A., Urich, C., Sitzenfrei, R., Kleidorfer, M., Rauch, W. and McCarthy, D.T., 2013. Modelling Interactions Between Lot-Scale Decentralised Water Infrastructure and Urban Form - a Case Study on Infiltration Systems. Water Resources Management 27(14), 4845-4863.

Ball, J., M. , Babister, R., Nathan, W., Weeks, E., Weinmann, M. and Retallick, I.T., 2016. Australian Rainfall and Runoff: A Guide to Flood Estimation. Commonwealth of Australia. Burns, M.J., Fletcher, T.D., Duncan, H.P., Hatt, B.E., Ladson, A.R. and Walsh, C.J., 2015. The performance of rainwater tanks for stormwater retention and water supply at the household scale: an empirical study. Hydrological Processes 29, 152-160. Campisano, A., Butler, D., Ward, S., Burns, M.J., Friedler, E., DeBusk, K., Fisher-Jeffes, L.N., Ghisi, E., Rahman, A., Furumai, H. and Han, M., 2017. Urban rainwater harvesting systems: Research, implementation and future perspectives. Water Research 115, 195-209. Carr, R. and Podger, G., 2012. eWater source - Australia's next generation IWRM modelling platform Engineers Australia, Barton, ACT:

Chiew, F.H.S. and McMahon, T.A., 1997. Modelling daily runoff and pollutant load from urban catchments Water (AWWA Journal) 24(16-17).

Cunge, J.A., 1969. On The Subject Of A Flood Propagation Computation Method (Musklngum Method). Journal of Hydraulic Research 7(2), 205-230.

Davis, A., Hunt, W., Traver, R. and Clar, M., 2009. Bioretention Technology: Overview of Current Practice and Future Needs. Journal of Environmental Engineering 135(3), 109-117. Davis, A.P., 2007. Field performance of bioretention: Water quality. Environmental Engineering Science 24(8), 1048-1064.

Deletic, A., Zhang, K., Jamali, B., Charette-Castonguay, A., Kuller, M., Prodanovic, V. and Bach, M.P., 2018. Modelling to support the planning of sustainable urban water systems, Palermo, Italy.

Dotto, C.B., Deletic, A. and Fletcher, T.D., 2009. Analysis of parameter uncertainty of a flow and quality stormwater model. Water Sci Technol 60(3), 717-725.

Dotto, C.B., Deletic, A. and McCarthy, D.T., 2013. Uncertainty analysis in urban drainage modelling: should we break our back for normally distributed residuals? Water Sci Technol 68(6), 1271-1279.

Elliott, A. and Trowsdale, S., 2007. A review of models for low impact urban stormwater drainage. Environmental Modelling \& Software 22(3), 394-405. eWater, 2014. Model for urban stormwater improvement conceptualisation (MUSIC Version $6)$. 
Fisher-Jeffes L., Carden K., Armitage N.P. and K., W., 2017. Stormwater harvesting: Improving water security in South Africa's urban areas. South African Journal of Science 113.

Fletcher, T., 2004. Stormwater Flow and Quality and the Effectiveness of Non-proprietary for Catchment Hydrology.

Fletcher, T., Mitchell, V., Deletic, A., Ladson, T. and Seven, A., 2007. Is stormwater harvesting beneficial to urban waterway environmental flows? Water Science \& Technology 55(4), 265-272.

Fletcher, T.D., Shuster, W., Hunt, W.F., Ashley, R., Butler, D., Arthur, S., Trowsdale, S., Barraud, S., Semadeni-Davies, A., Bertrand-Krajewski, J.-L., Mikkelsen, P.S., Rivard, G., Uhl, M., Dagenais, D. and Viklander, M., 2015. SUDS, LID, BMPs, WSUD and more - The evolution and application of terminology surrounding urban drainage. Urban Water Journal 12(7), 525-542.

Hammes, G., Thives, L.P. and Ghisi, E., 2018. Application of stormwater collected from porous asphalt pavements for non-potable uses in buildings. Journal of Environmental Management 222, 338-347.

Hatt, B.E., Deletic, A. and Fletcher, T.D., 2006. Integrated treatment and recycling of stormwater: a review of Australian practice. Journal of Environmental Management 79(1), 102-113.

Hatt, B.E., Fletcher, T.D. and Deletic, A., 2009. Hydrologic and pollutant removal performance of stormwater biofiltration systems at the field scale. Journal of Hydrology 365(3-4), 310-321.

Imteaz, M.A., Ahsan, A., Rahman, A. and Mekanik, F., 2013. Modelling stormwater treatment systems using MUSIC: Accuracy. Resources Conservation and Recycling 71, 1521.

Jeng, H.A.C., Englande, A.J., Bakeer, R.M. and Bradford, H.B., 2005. Impact of urban stormwater runoff on estuarine environmental quality. Estuarine, Coastal and Shelf Science 63(4), 513-526.

Jun, X., YongYong, Z., LiHua, X., Shan, H., LongFeng, W. and ZhongBo, Y., 2017.

Opportunities and challenges of the Sponge City construction related to urban water issues in China. SCIENCE CHINA Earth Sciences 60(4), 652.

Kuller, M., Bach, P.M., Ramirez-Lovering, D. and Deletic, A., 2018a. What drives the location choice for water sensitive infrastructure in Melbourne, Australia? Landscape and Urban Planning 175, 92-101.

Kuller, M., Farrelly, M., Deletic, A. and Bach, P.M., 2018b. Building effective Planning Support Systems for green urban water infrastructure-Practitioners' perceptions.

Environmental Science \& Policy 89, 153-162.

Leroy, M.-c., Portet-Koltalo, F., Legras, M., Lederf, F., Moncond'huy, V., Polaert, I. and Marcotte, S., 2016. Performance of vegetated swales for improving road runoff quality in a moderate traffic urban area. Science of The Total Environment 566-567, 113-121.

Malaviya, P. and Singh, A., 2012. Constructed Wetlands for Management of Urban Stormwater Runoff. Critical Reviews in Environmental Science and Technology 42(20), 2153-2214.

Melbourne Water, 2010. MUSIC Guidelines. Melbourne Water.

Mitchell, V.G., 2004. Integrated urban water management : a review of current Australian practice. CSIRO.

Mitchell, V.G., Deletic, A., Fletcher, T.D., Hatt, B. and McCarthy, D.T., 2007. Achieving Multiple Benefits from Urban Stormwater Harvesting. Water Science \& Technology 55(4), 135-144. 
Mitchell, V.G., Hatt, B.E., Deletic, A., Fletcher, T.D., McCarthy, D.T. and Magyar, M., 2006. Integrated Stormwater Treatment and Harvesting: Technical Guidance Report. Institute for Sustainable Water Resources. Monash University, Australia.

Mitchell, V.G., Mein, R.G. and McMahon, T.A., 2001. Modelling the urban water cycle. Environmental Modelling \& Software 16(7), 615-629. Moore, T.L.C. and Hunt, W.F., 2013. Predicting the carbon footprint of urban stormwater infrastructure. Ecological Engineering 58, 44-51. Polyakov, M., Iftekhar, S., Zhang, F. and Fogarty, J., 2015. The amenity value of water sensitive urban infrastructure: A case study on rain gardens. , Rotorua, N.Z. Rossman, L.A., 2017. Storm water management model (SWMM), USEPA. Management Benefits of Residential Rainwater Harvesting in U.S. Cities. JAWRA Journal of the American Water Resources Association 49(4), 810-824. VSC, 1999. Urban Stormwater: Best Practice Environmental Management Guidelines (BPEMG), CSIRO Publishing.

Wong, T.H., Fletcher, T.D., Duncan, H.P., Coleman, J.R. and Jenkins, G.A., 2002. A model for urban stormwater improvement conceptualisation. Global Solutions for Urban Drainage 813.

Wong, T.H.F., Allen, R., Brown, R.R., Deletic, A., Gangadharan, L., Gernjak, W., Jakob, C., Johnstone, P., Reeder, M., Tapper, N., Vietz, G. and Walsh, C., 2013. Blueprint2013 Stormwater Management in a Water Sensitive City. CRC for Water Sensitive Cities, Melbourne.

643 Xu, T., Jia, H., Wang, Z., Mao, X. and Xu, C., 2017. SWMM-based methodology for blockscale LID-BMPs planning based on site-scale multi-objective optimization: a case study in Tianjin. Frontiers of Environmental Science \& Engineering 11(4), 1.

Zhang, K., Deletic, A., Page, D. and McCarthy, D.T., 2015. Surrogates for herbicide removal in stormwater biofilters. Water Research 81(0), 64-71.

Zhang, K., Manuelpillai, D., Raut, B., Deletic, A. and Bach, P.M., 2019. Evaluating the reliability of stormwater treatment systems under various future climate conditions. Journal of Hydrology 568, 57-66.

651 Zhang, Z., Rengel, Z., Liaghati, T., Antoniette, T. and Meney, K., 2011. Influence of plant 652 species and submerged zone with carbon addition on nutrient removal in stormwater biofilter. 653 Ecological Engineering 37(11), 1833-1841. 
Table 1. Summary of variables tested and their selected values

\begin{tabular}{|c|c|c|}
\hline Category & Variables & Selected Values \\
\hline Climate & $\begin{array}{l}\text { City } \\
\text { Rainfall Length (years) }\end{array}$ & $\begin{array}{l}\text { Melbourne, Brisbane, Perth } \\
1 \text { year }(1959), 10 \text { years }(2000-2009)\end{array}$ \\
\hline Catchment & $\begin{array}{l}\text { Area [ha] } \\
\text { Imperviousness [\%] }\end{array}$ & $\begin{array}{l}1 \text { ha, } 10 \text { ha, } 100 \text { ha } \\
100 \%\end{array}$ \\
\hline Harvesting & $\begin{array}{l}\text { Reliability of Supply [\%] } \\
\text { Demand Pattern } \\
\text { Extraction rate [\% of inflow] }\end{array}$ & $\begin{array}{l}60 \%, 80 \%, 90 \% \\
\text { Constant, Seasonal (scaled by Potential evapotranspiration) } \\
25 \%, 50 \%, 75 \%, 100 \%\end{array}$ \\
\hline Treatment & $\begin{array}{l}\text { Pollutant Type } \\
\text { Reduction Target }[\%]^{2)} \\
\text { System Type } \\
\text { System Design Configuration } \\
\text { Treatment train }\end{array}$ & $\begin{array}{l}\text { Total Suspend Solids (TSS), Total Nitrogen (TN), Total Phosphorus (TP) } \\
\text { TSS 95\%, 85\%, 60\% } \\
\text { TP } \quad 60 \%, 45 \%, 20 \% \\
\text { TN } 55 \%, 45 \%, 20 \% \\
\text { Biofilter, Wetland, Pond } \\
\text { Different designs for each system }{ }^{3)} \text { : } \\
\text { - } \quad \text { Biofilter A: extended detention depth (EDD) of } 100 \mathrm{~mm} \text {, filter } \\
\quad \text { media depth (FD) of } 500 \mathrm{~mm} \\
\text { - } \quad \text { Biofilter B: EDD - } 500 \mathrm{~mm} \text {, FD -300 mm } \\
\text { - } \quad \text { Biofilter C: EDD - } 300 \mathrm{~mm} \text {, FD -500 mm } \\
\text { - } \quad \text { Wetland A: EDD - } 750 \mathrm{~mm} \text {, detention time } 72 \mathrm{hr} \\
\text { - } \quad \text { Wetland C: EDD - } 250 \mathrm{~mm} \text {, detention time } 48 \mathrm{hr} \\
\text { - } \quad \text { Pond A: EDD - } 1000 \mathrm{~mm} \text {, detention time } 72 \mathrm{hr} \\
\text { - } \quad \text { Pond B: EDD - } 2000 \mathrm{~mm} \text {, detention time } 72 \mathrm{hr} \\
\text { - } \quad \text { Pond C: EDD - } 3000 \mathrm{~mm} \text {, detention time } 24 \mathrm{hr} \\
\text { Treatment trains include (first two used for sensitive testing scenarios and } \\
\text { the rest for validation scenarios): } \\
\text { TT_1: wetland A+ storage tank } \\
\text { TT_2: vegetated swales + biofilter A+ storage tank } \\
\text { TT_V1_A: sedimentation pond + biofilter A + storage tank } \\
\text { TT_V1_C: sedimentation pond + biofilter C + storage tank } \\
\text { TT_V2_A: wetland A + pond storage } \\
\text { TT_V2_C: wetland C + pond storage }\end{array}$ \\
\hline
\end{tabular}

1) To allow more robust testing of climate impact both spatially and temporary, for each city, two different rainfall series were used: 1-year rainfall data from Year 1959 (a typical year representing long term average in these cities), and 10-year rainfall between 2000 and 2009 (which had long term drought period; all 6-minute timestep). Refer to the supplementary document for the details and statistics of different climate types. ${ }^{2)}$ BPEM guideline (VSC, 1999) requires load reduction of $85 \%$ for TSS, $45 \%$ for TP and 45\% for TN, and the selected targets in this study had a good coverage of what is required. ${ }^{3)}$ Details of the all the designs are given in Table S1- Table S3 of the Supplementary document. Both design A and B were used in the sensitivity testing of "design-based" data set, while only design A was used in the sensitivity testing of Stage 1, Stage 2 "targetbased" data set, and the treatment train scenarios. Design C was only used in the empirical relationship validation scenarios introduced below. 
Table 3 Performance of the proposed empirical relationship: fitted parameter ( $m$ and $b_{\text {thresh }}$ ) values estimated and modelled IAO values from the sensitivity testing

\begin{tabular}{|c|c|c|c|c|c|c|c|c|c|}
\hline System & Pollutant & Target & $\begin{array}{l}\text { Modelled } \\
\text { IAO [\%] } \\
\end{array}$ & $\mathbf{m}$ & $\mathbf{b}_{\text {thresh }}$ & $\mathbf{R}^{2}$ & $\begin{array}{l}\text { Estimated } \\
\text { IAO [\%] }\end{array}$ & $\begin{array}{l}p \text { value } \\
(\mathrm{t} \text { test) }\end{array}$ & $\Delta \boldsymbol{I} \boldsymbol{A} \boldsymbol{O}^{I}$ \\
\hline \multirow[t]{9}{*}{ Biofilter A } & TSS & 95 & $0.0 \%$ & 0.025 & 0.507 & 0.956 & $2.5 \%$ & 0.208 & $2.50 \%$ \\
\hline & TSS & 85 & $1.0 \%$ & 0.009 & 0.246 & 0.663 & $0.9 \%$ & 0.484 & $-0.10 \%$ \\
\hline & TSS & 60 & $0.7 \%$ & 0.006 & 0.160 & 0.892 & $0.6 \%$ & 0.380 & $-0.10 \%$ \\
\hline & $\mathrm{TP}$ & 60 & $61.2 \%$ & 0.616 & -0.020 & 0.996 & $61.6 \%$ & 0.877 & $0.40 \%$ \\
\hline & $\mathrm{TP}$ & 45 & $56.3 \%$ & 0.566 & -0.015 & 0.999 & $56.6 \%$ & 0.929 & $0.30 \%$ \\
\hline & $\mathrm{TP}$ & 20 & $27.0 \%$ & 0.269 & -0.017 & 0.999 & $26.9 \%$ & 0.920 & $-0.10 \%$ \\
\hline & $\mathrm{TN}$ & 55 & $25.0 \%$ & 0.257 & -0.014 & 0.994 & $25.7 \%$ & 0.933 & $0.70 \%$ \\
\hline & TN & 45 & $27.7 \%$ & 0.276 & 0.004 & 0.998 & $27.6 \%$ & 0.980 & $-0.10 \%$ \\
\hline & $\mathrm{TN}$ & 20 & $26.8 \%$ & 0.267 & 0.000 & 0.997 & $26.7 \%$ & 0.999 & $-0.10 \%$ \\
\hline \multirow[t]{3}{*}{ Biofilter B } & TSS & 85 & $1.8 \%$ & 0.018 & 0.175 & 0.894 & $1.8 \%$ & 0.332 & $0.00 \%$ \\
\hline & $\mathrm{TP}$ & 45 & $56.3 \%$ & 0.570 & -0.006 & 0.995 & $57.0 \%$ & 0.970 & $0.70 \%$ \\
\hline & TN & 45 & $27.7 \%$ & 0.280 & -0.004 & 0.994 & $28.0 \%$ & 0.982 & $0.30 \%$ \\
\hline \multirow{9}{*}{ Wetland A } & TSS & 95 & $3.2 \%$ & 0.032 & 0.000 & 0.999 & $3.2 \%$ & 1.000 & $0.00 \%$ \\
\hline & TSS & 85 & $4.3 \%$ & 0.043 & 0.014 & 0.998 & $4.3 \%$ & 0.957 & $0.00 \%$ \\
\hline & TSS & 60 & $6.1 \%$ & 0.060 & -0.010 & 0.999 & $6.0 \%$ & 0.969 & $-0.10 \%$ \\
\hline & $\mathrm{TP}$ & 60 & $21.8 \%$ & 0.218 & 0.006 & 1.000 & $21.8 \%$ & 0.983 & $0.00 \%$ \\
\hline & $\mathrm{TP}$ & 45 & $25.0 \%$ & 0.254 & -0.003 & 0.997 & $25.4 \%$ & 0.990 & $0.40 \%$ \\
\hline & $\mathrm{TP}$ & 20 & $31.7 \%$ & 0.308 & -0.040 & 0.993 & $30.8 \%$ & 0.876 & $-0.90 \%$ \\
\hline & $\mathrm{TN}$ & 55 & $72.4 \%$ & 0.720 & 0.002 & 1.000 & $72.0 \%$ & 0.995 & $-0.40 \%$ \\
\hline & $\mathrm{TN}$ & 45 & $89.2 \%$ & 0.893 & 0.002 & 1.000 & $89.3 \%$ & 0.992 & $0.10 \%$ \\
\hline & TN & 20 & $127.1 \%$ & 1.267 & 0.003 & 1.000 & $126.7 \%$ & 0.992 & $-0.40 \%$ \\
\hline \multirow[t]{3}{*}{ Wetland B } & TSS & 85 & $3.1 \%$ & 0.031 & 0.006 & 0.999 & $3.1 \%$ & 0.980 & $0.00 \%$ \\
\hline & $\mathrm{TP}$ & 45 & $19.6 \%$ & 0.196 & 0.000 & 1.000 & $19.6 \%$ & 1.000 & $0.00 \%$ \\
\hline & $\mathrm{TN}$ & 45 & $59.6 \%$ & 0.597 & 0.009 & 1.000 & $59.7 \%$ & 0.971 & $0.10 \%$ \\
\hline \multirow[t]{9}{*}{ Pond A } & TSS & 95 & $5.3 \%$ & 0.053 & 0.004 & 1.000 & $5.3 \%$ & 0.988 & $0.00 \%$ \\
\hline & TSS & 85 & $15.0 \%$ & 0.152 & 0.022 & 0.998 & $15.2 \%$ & 0.931 & $0.20 \%$ \\
\hline & TSS & 60 & $22.7 \%$ & 0.232 & 0.014 & 0.998 & $23.2 \%$ & 0.957 & $0.50 \%$ \\
\hline & TP & 60 & $48.5 \%$ & 0.490 & 0.011 & 0.999 & $49.0 \%$ & 0.966 & $0.50 \%$ \\
\hline & $\mathrm{TP}$ & 45 & $55.0 \%$ & 0.557 & 0.009 & 0.999 & $55.7 \%$ & 0.973 & $0.70 \%$ \\
\hline & $\mathrm{TP}$ & 20 & $55.5 \%$ & 0.553 & -0.010 & 0.999 & $55.3 \%$ & 0.968 & $-0.20 \%$ \\
\hline & $\mathrm{TN}$ & 55 & $80.3 \%$ & 0.804 & 0.015 & 0.999 & $80.4 \%$ & 0.955 & $0.10 \%$ \\
\hline & $\mathrm{TN}$ & 45 & $117.5 \%$ & 1.181 & 0.020 & 0.998 & $118.1 \%$ & 0.939 & $0.60 \%$ \\
\hline & TN & 20 & $232.0 \%$ & 2.340 & 0.013 & 0.999 & $234.0 \%$ & 0.960 & $2.00 \%$ \\
\hline \multirow[t]{3}{*}{ Pond B } & TSS & 85 & $1.7 \%$ & 0.017 & 0.034 & 0.995 & $1.7 \%$ & 0.897 & $0.00 \%$ \\
\hline & $\mathrm{TP}$ & 45 & $79.5 \%$ & 0.809 & 0.018 & 0.998 & $80.9 \%$ & 0.943 & $1.40 \%$ \\
\hline & $\mathrm{TN}$ & 45 & $121.8 \%$ & 1.219 & 0.015 & 0.999 & $121.9 \%$ & 0.952 & $0.10 \%$ \\
\hline \multirow{3}{*}{$\begin{array}{l}\text { TT_1 } \\
\text { (Wetland A + } \\
\text { Storage tank) } \\
\end{array}$} & TSS & 85 & $4.3 \%$ & 0.042 & -0.082 & 0.974 & $4.2 \%$ & 0.754 & $-0.10 \%$ \\
\hline & TP & 45 & $24.9 \%$ & 0.240 & -0.080 & 0.975 & $24.0 \%$ & 0.758 & $-0.90 \%$ \\
\hline & $\mathrm{TN}$ & 45 & $82.2 \%$ & 0.805 & -0.054 & 0.988 & $80.5 \%$ & 0.834 & $-1.70 \%$ \\
\hline \multirow{3}{*}{$\begin{array}{l}\text { TT_2 } \\
\text { (Vegetated swales } \\
\text { + Biofilter A } \\
\text { + Storage tank) }\end{array}$} & TSS & 85 & $1.0 \%$ & 0.010 & 0.096 & 0.955 & $1.0 \%$ & 0.714 & $0.00 \%$ \\
\hline & $\mathrm{TP}$ & 45 & $40.4 \%$ & 0.396 & -0.055 & 0.987 & $39.6 \%$ & 0.830 & $-0.80 \%$ \\
\hline & $\mathrm{TN}$ & 45 & $26.8 \%$ & 0.270 & 0.004 & 1.000 & $27.0 \%$ & 0.989 & $0.20 \%$ \\
\hline
\end{tabular}

I) $\triangle I A O=$ Estimated IAO - Modelled IAO, where" estimated IAO" was from MUSIC simulation, and "Modelled IAO" was

from the proposed linear regression model 
Table 4 Summary of the validation results

\begin{tabular}{|c|c|c|c|c|c|c|c|c|}
\hline Scenarios & Pollutant & Target & $\boldsymbol{P}_{\text {ext }}$ & $\begin{array}{c}\boldsymbol{m} \\
\text { value }^{1)}\end{array}$ & $\mathbf{b}_{\text {tresh }}^{2)}$ & $\begin{array}{l}\text { Baseline } \\
\text { IAO [\%] }\end{array}$ & $\begin{array}{l}\text { Modelled } \\
\text { IAO [\%] }\end{array}$ & $\begin{array}{c}\Delta \text { IAO (Baseline - } \\
\text { modelled) }\end{array}$ \\
\hline \multirow[t]{3}{*}{ Biofilter A } & TSS & 85 & 0.85 & 0.009 & 0.40 & $0.4 \%$ & $0.8 \%$ & $-0.4 \%$ \\
\hline & TP & 45 & 0.65 & 0.566 & 0.00 & $40.0 \%$ & $36.8 \%$ & $3.2 \%$ \\
\hline & TN & 45 & 0.55 & 0.276 & 0.00 & $13.0 \%$ & $15.2 \%$ & $-2.2 \%$ \\
\hline \multirow{3}{*}{ Biofilter C } & TSS & 85 & 0.85 & 0.009 & 0.40 & $0.7 \%$ & $0.8 \%$ & $-0.1 \%$ \\
\hline & TP & 45 & 0.65 & 0.566 & 0.00 & $55.0 \%$ & $36.8 \%$ & $18.2 \%$ \\
\hline & TN & 45 & 0.55 & 0.276 & 0.00 & $16.5 \%$ & $15.2 \%$ & $1.3 \%$ \\
\hline \multirow[t]{3}{*}{ Biofilter C } & TSS & $70^{3)}$ & 0.85 & 0.007 & 0.00 & $0.3 \%$ & $0.6 \%$ & $-0.3 \%$ \\
\hline & TP & 30 & 0.65 & 0.388 & 0.00 & $51.1 \%$ & $25.2 \%$ & $25.9 \%$ \\
\hline & TN & 30 & 0.55 & 0.271 & 0.00 & $15.9 \%$ & $14.9 \%$ & $1.0 \%$ \\
\hline \multirow[t]{3}{*}{ Wetland A } & TSS & 85 & 0.85 & 0.043 & 0.00 & $3.7 \%$ & $3.7 \%$ & $0.0 \%$ \\
\hline & $\mathrm{TP}$ & 45 & 0.65 & 0.254 & 0.00 & $17.4 \%$ & $16.5 \%$ & $0.9 \%$ \\
\hline & TN & 45 & 0.55 & 0.893 & 0.00 & $50.2 \%$ & $49.1 \%$ & $1.1 \%$ \\
\hline \multirow[t]{3}{*}{ Wetland C } & TSS & 85 & 0.85 & 0.043 & 0.00 & $3.6 \%$ & $3.7 \%$ & $-0.1 \%$ \\
\hline & $\mathrm{TP}$ & 45 & 0.65 & 0.254 & 0.00 & $17.1 \%$ & $16.5 \%$ & $0.6 \%$ \\
\hline & TN & 45 & 0.55 & 0.893 & 0.00 & $48.9 \%$ & $49.1 \%$ & $-0.2 \%$ \\
\hline \multirow[t]{3}{*}{ Wetland C } & TSS & 70 & 0.85 & 0.053 & 0.00 & $3.0 \%$ & $4.5 \%$ & $-1.5 \%$ \\
\hline & $\mathrm{TP}$ & 30 & 0.65 & 0.287 & 0.00 & $16.5 \%$ & $18.7 \%$ & $-2.2 \%$ \\
\hline & TN & 30 & 0.55 & 1.118 & 0.00 & $60.1 \%$ & $61.5 \%$ & $-1.4 \%$ \\
\hline \multirow[t]{3}{*}{ Pond A } & TSS & 85 & 0.85 & 0.152 & 0.00 & $13.0 \%$ & $12.9 \%$ & $0.1 \%$ \\
\hline & $\mathrm{TP}$ & 45 & 0.65 & 0.557 & 0.00 & $37.4 \%$ & $36.2 \%$ & $1.2 \%$ \\
\hline & TN & 45 & 0.55 & 1.181 & 0.00 & $62.2 \%$ & $65.0 \%$ & $-2.8 \%$ \\
\hline \multirow[t]{3}{*}{ Pond C } & TSS & 85 & 0.85 & 0.152 & 0.00 & $12.2 \%$ & $12.9 \%$ & $-0.7 \%$ \\
\hline & TP & 45 & 0.65 & 0.557 & 0.00 & $38.9 \%$ & $36.2 \%$ & $2.7 \%$ \\
\hline & TN & 45 & 0.55 & 1.181 & 0.00 & $61.2 \%$ & $65.0 \%$ & $-3.8 \%$ \\
\hline \multirow{3}{*}{ Pond C } & TSS & 70 & 0.85 & 0.200 & 0.00 & $16.0 \%$ & $17.0 \%$ & $-1.0 \%$ \\
\hline & TP & 30 & 0.65 & 0.555 & 0.00 & $34.4 \%$ & $36.1 \%$ & $-1.7 \%$ \\
\hline & TN & 30 & 0.55 & 1.876 & 0.00 & $99.6 \%$ & $103.2 \%$ & $-3.6 \%$ \\
\hline \multirow{3}{*}{$\begin{array}{l}\left.\text { TT_V1_A }{ }^{3}\right) \\
\text { (Sed. Pond + Biofilter } \\
\text { A + storage tank) }\end{array}$} & TSS & 85 & 0.85 & 0.009 & 0.00 & $0.3 \%$ & $0.4 \%$ & $-0.5 \%$ \\
\hline & TP & 45 & 0.65 & 0.566 & 0.00 & $40.1 \%$ & $36.8 \%$ & $3.3 \%$ \\
\hline & TN & 45 & 0.55 & 0.276 & 0.00 & $12.2 \%$ & $15.2 \%$ & $-3.0 \%$ \\
\hline \multirow{3}{*}{$\begin{array}{l}\text { TT_V1_C (Sed. Pond } \\
\text { + Biofilter C + storage } \\
\text { tank) }\end{array}$} & TSS & 85 & 0.85 & 0.009 & 0.00 & $0.3 \%$ & $0.4 \%$ & $-0.5 \%$ \\
\hline & $\mathrm{TP}$ & 45 & 0.65 & 0.566 & 0.00 & $41.0 \%$ & $36.8 \%$ & $4.2 \%$ \\
\hline & TN & 45 & 0.55 & 0.276 & 0.00 & $14.7 \%$ & $15.2 \%$ & $-0.5 \%$ \\
\hline \multirow{3}{*}{$\begin{array}{l}\text { TT_V1_C } \\
\text { (Sed. Pond + Biofilter } \\
\text { C + storage tank) }\end{array}$} & TSS & 70 & 0.85 & 0.007 & 0.00 & $0.5 \%$ & $0.4 \%$ & $0.1 \%$ \\
\hline & $\mathrm{TP}$ & 30 & 0.65 & 0.389 & 0.00 & $42.1 \%$ & $25.3 \%$ & $16.8 \%$ \\
\hline & $\mathrm{TN}$ & 30 & 0.55 & 0.271 & 0.00 & $16.0 \%$ & $14.9 \%$ & $1.1 \%$ \\
\hline \multirow{3}{*}{$\begin{array}{l}\text { TT_V2_A } \\
\text { (Wetland A + Pond } \\
\text { Storage) }\end{array}$} & TSS & 85 & 0.85 & 0.152 & 0.00 & $12.5 \%$ & $12.9 \%$ & $-0.4 \%$ \\
\hline & TP & 45 & 0.65 & 0.557 & 0.00 & $35.7 \%$ & $36.2 \%$ & $-0.5 \%$ \\
\hline & TN & 45 & 0.55 & 1.181 & 0.00 & $63.1 \%$ & $65.0 \%$ & $-1.9 \%$ \\
\hline \multirow{3}{*}{$\begin{array}{l}\text { TT_V2_C } \\
\text { (Wetland C + Pond } \\
\text { Storage) }\end{array}$} & TSS & 85 & 0.85 & 0.152 & 0.00 & $12.9 \%$ & $12.9 \%$ & $0.0 \%$ \\
\hline & TP & 45 & 0.65 & 0.557 & 0.00 & $36.6 \%$ & $36.2 \%$ & $0.4 \%$ \\
\hline & TN & 45 & 0.55 & 1.181 & 0.00 & $67.1 \%$ & $65.0 \%$ & $2.1 \%$ \\
\hline \multirow{3}{*}{$\begin{array}{l}\text { TT_V2_C } \\
\text { (Wetland C + Pond } \\
\text { Storage) }\end{array}$} & TSS & 70 & 0.85 & 0.152 & 0.00 & $12.8 \%$ & $12.9 \%$ & $-0.1 \%$ \\
\hline & TP & 30 & 0.65 & 0.557 & 0.00 & $37.4 \%$ & $36.2 \%$ & $1.2 \%$ \\
\hline & "TN & 30 & 0.55 & 1.181 & 0.00 & $68.3 \%$ & $65.0 \%$ & $3.3 \%$ \\
\hline
\end{tabular}

${ }^{1)} \mathrm{m}$ values are looked up from Table 3 with the correspondence pollutant type and target. For systems with different design configurations (e.g., configuration C) from Table 3, the values for configuration A were taken as approximate as system design was found to be less sensitive. For the pollutant target that was not covered from sensitivity estimations, simple linear interpolations were conducted to derive $m$ values.

${ }^{2)} b_{\text {tresh }}$ values were set to zeros as according to the discussion in the last section (the main treatment systems are biofilters and wetlands).

${ }^{3)}$ Sedimentation pond was only used for reducing TSS concentrations to $50 \mathrm{mg} / \mathrm{L}$. 
Table 2 Impact of variables on Impervious Area Offset (IAO) - results from Stage 1 sensitivity testing

\begin{tabular}{|c|c|c|c|c|c|c|}
\hline City & $\begin{array}{l}\text { Climate } \\
\text { length }\end{array}$ & $\begin{array}{l}\text { Impervious } \\
\text { area [ha] }\end{array}$ & $\begin{array}{c}\text { Supply } \\
\text { reliability [\%] }\end{array}$ & $\begin{array}{l}\text { Reduction } \\
\text { target [\%] }\end{array}$ & $\begin{array}{c}\text { Reuse } \\
\text { pattern }\end{array}$ & $\begin{array}{l}\text { Impervious Area } \\
\text { Offset (IAO) [\%] }\end{array}$ \\
\hline \multicolumn{7}{|c|}{ (a) Impact of climate variability } \\
\hline \multirow{2}{*}{ Brisbane } & $1 \mathrm{yr}$ & \multirow{6}{*}{10} & \multirow{6}{*}{80} & \multirow{6}{*}{ TSS 85} & \multirow{6}{*}{ Constant } & $0.48 \%$ \\
\hline & $10 \mathrm{yrs}$ & & & & & $1.22 \%$ \\
\hline \multirow{2}{*}{ Perth } & $1 \mathrm{yr}$ & & & & & $0.92 \%$ \\
\hline & $10 \mathrm{yrs}$ & & & & & $1.00 \%$ \\
\hline \multirow{2}{*}{ Melbourne } & $1 \mathrm{yr}$ & & & & & $0.93 \%$ \\
\hline & $10 \mathrm{yrs}$ & & & & & $1.1 \%$ \\
\hline \multicolumn{7}{|c|}{ (b) Impact of catchment size } \\
\hline \multirow{9}{*}{ Melbourne } & \multirow{9}{*}{$10 \mathrm{yrs}$} & 1 & \multirow{9}{*}{80} & \multirow{3}{*}{ TSS 85} & \multirow{9}{*}{ Constant } & $0.9 \%$ \\
\hline & & 10 & & & & $1.01 \%$ \\
\hline & & 100 & & & & $1.03 \%$ \\
\hline & & 1 & & \multirow{3}{*}{ ТP 60} & & $66.7 \%$ \\
\hline & & 10 & & & & $66.7 \%$ \\
\hline & & 100 & & & & $66.7 \%$ \\
\hline & & 1 & & \multirow{3}{*}{$\mathrm{TN} 45$} & & $28.9 \%$ \\
\hline & & 10 & & & & $28.9 \%$ \\
\hline & & 100 & & & & $29.2 \%$ \\
\hline \multicolumn{7}{|c|}{ (c) Impact of demand pattern and supply reliability } \\
\hline \multirow{6}{*}{ Melbourne } & \multirow{6}{*}{$10 \mathrm{yrs}$} & \multirow{6}{*}{10} & \multirow{2}{*}{60} & \multirow{6}{*}{ TSS 85} & Constant & $0.94 \%$ \\
\hline & & & & & Seasonal & $0.93 \%$ \\
\hline & & & \multirow{2}{*}{80} & & Constant & $0.93 \%$ \\
\hline & & & & & Seasonal & $1.00 \%$ \\
\hline & & & \multirow{2}{*}{90} & & Constant & $0.93 \%$ \\
\hline & & & & & Seasonal & $1.10 \%$ \\
\hline
\end{tabular}

Note: All scenarios used an extraction rate of 100\% for biofilter design A (Table 1). 


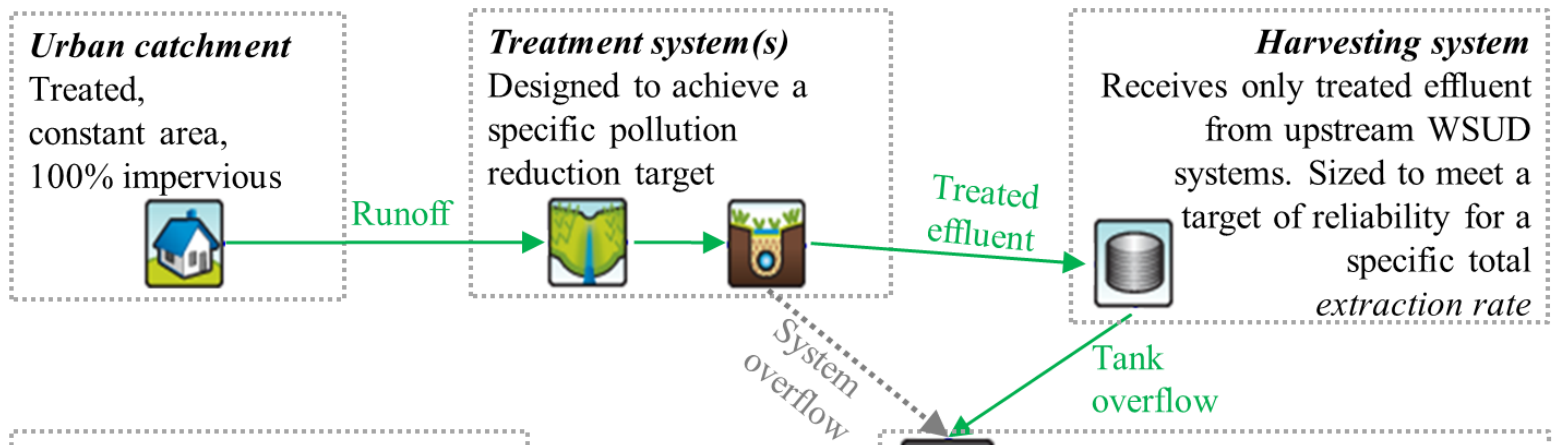

\section{Extra catchment}

Untreated, 100\% impervious, used to measure additional pollution reduction benefit of stormwater harvesting

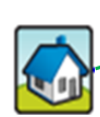

Final downstream point

Needs to meet specific pollution reduction target; receives runoff, treatment system overflow and tank overflow

Figure 1 Basic MUSIC model setup for assessing pollution reduction benefits of SWH 

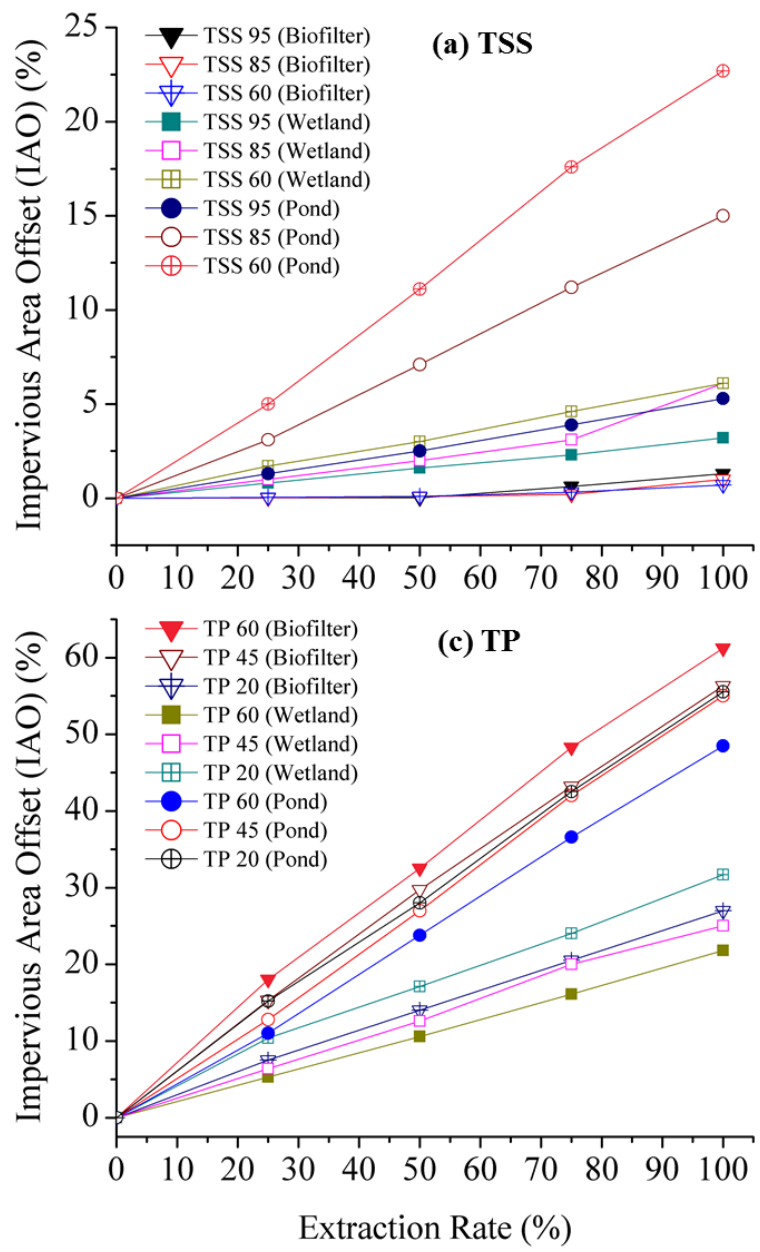

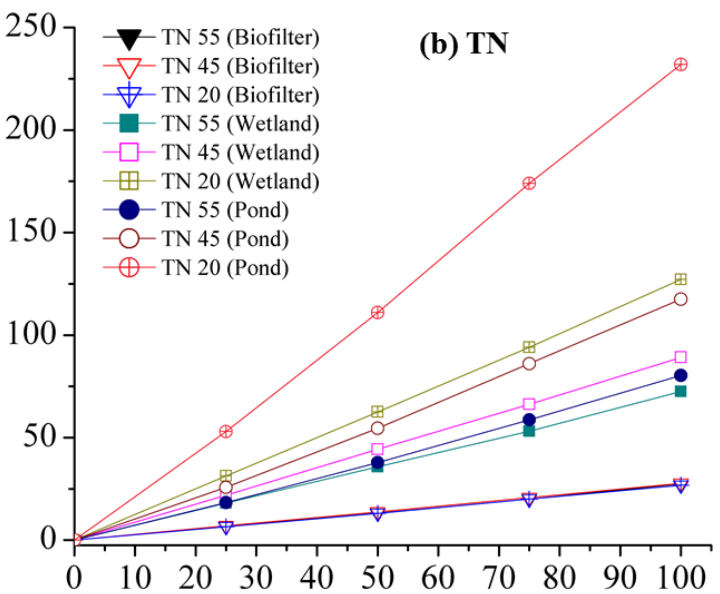

Extraction Rate (\%)

\section{(d) Pearson Correlations}

\begin{tabular}{lccccccc|c|c|} 
& $\begin{array}{c}\text { IAO } \\
(\%)\end{array}$ & $\begin{array}{c}\text { Pollutant System } \\
\text { Type }\end{array}$ & Type & $\begin{array}{c}\text { Extraction } \\
(\%)\end{array}$ & $\begin{array}{c}\text { TSS } \\
(\%)\end{array}$ & $\begin{array}{c}\text { TP } \\
(\%)\end{array}$ & $\begin{array}{c}\text { TN } \\
(\%)\end{array}$ \\
\hline IAO (\%) & 1 & & & & & & \\
\hline Pollutant Type & $.57^{*}$ & 1 & & & & & \\
\hline System Type & $.30^{*}$ & 0 & 1 & & & & \\
\hline Extraction (\%) & $.35^{*}$ & 0 & 0 & 1 & & \\
\hline TSS (\%) & $-.80^{*}$ & $-.72^{*}$ & -0.09 & $-.28^{*}$ & 1 & \\
\hline TP (\%) & $-.71^{*}$ & $-.66^{*}$ & $-.38^{*}$ & 0.07 & $.75^{*}$ & 1 & \\
\hline TN (\%) & $-.31^{*}$ & $-.58^{*}$ & $.42^{*}$ & $.30^{*}$ & $.55^{*} .43^{*}$ & 1 \\
\hline
\end{tabular}

* Correlation is significant at the 0.01 level (2-tailed).

Figure 2 Relationship between extraction rates and IAO for different system type, pollutant, and reduction targets: results from the "target-based" data set. 

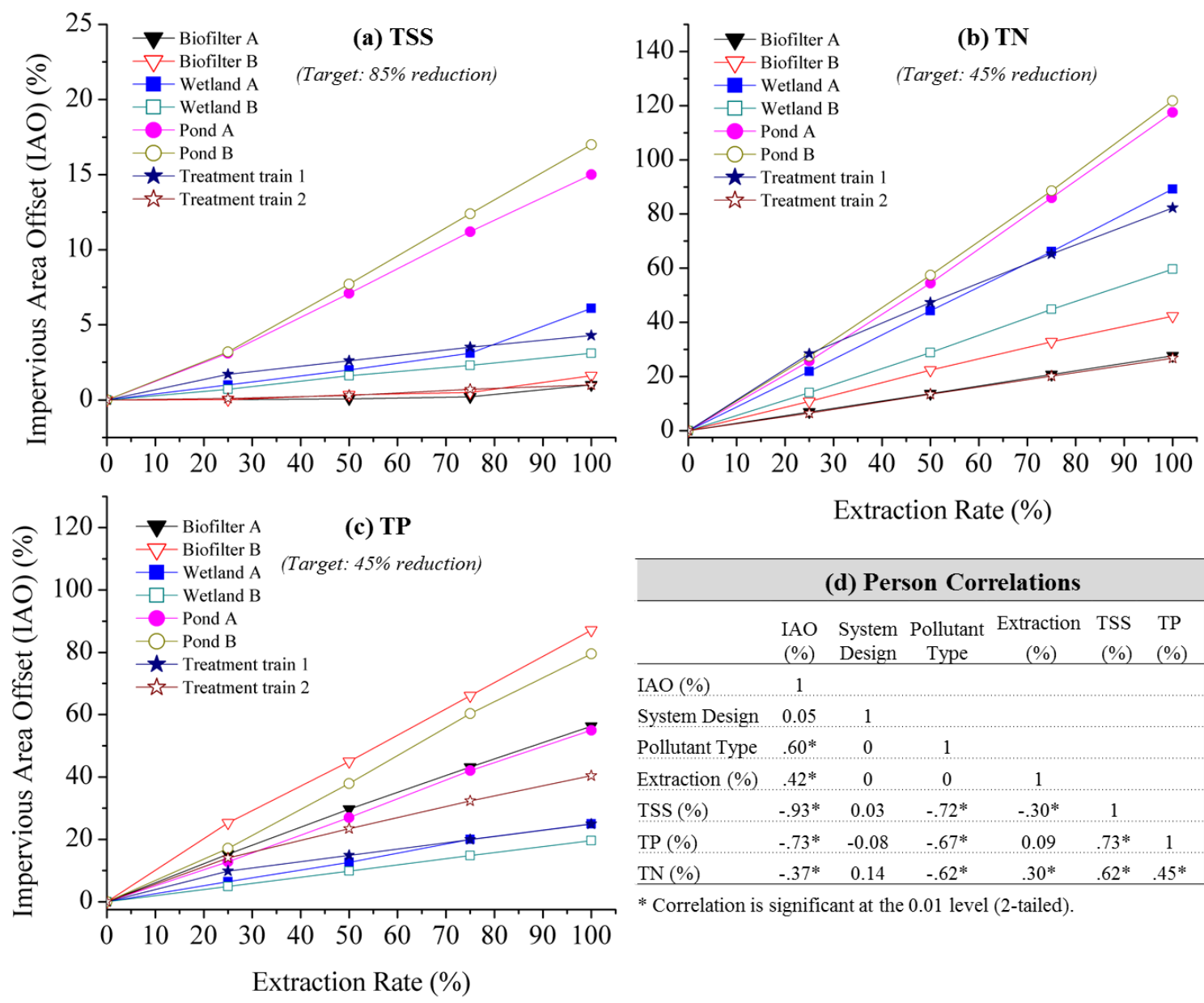

Extraction Rate (\%)

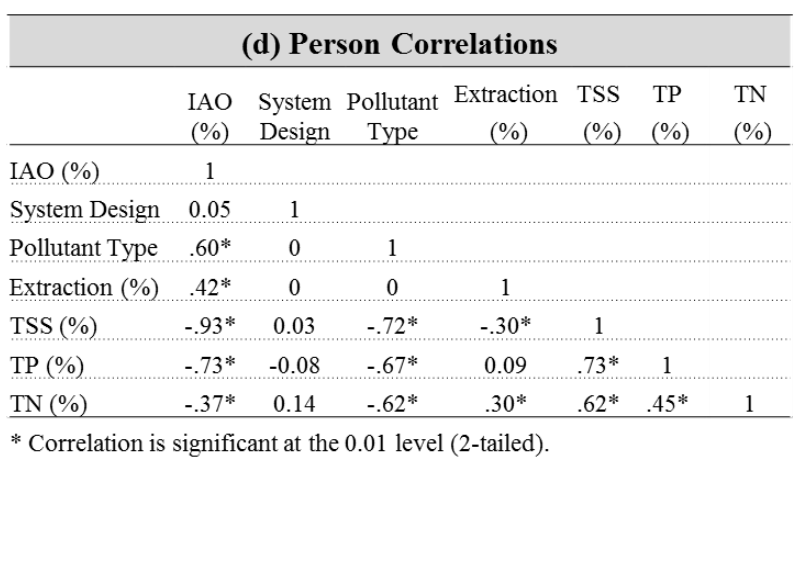

Figure 3 Relationship between extraction rates and IAO for different system type and design, pollutant type, and reduction targets: results from the "design-based" data set. The same treatment targets were used for the figures (i.e., TSS $85 \%$, TP $45 \%$ and TN $45 \%$ ). 
Figure 4
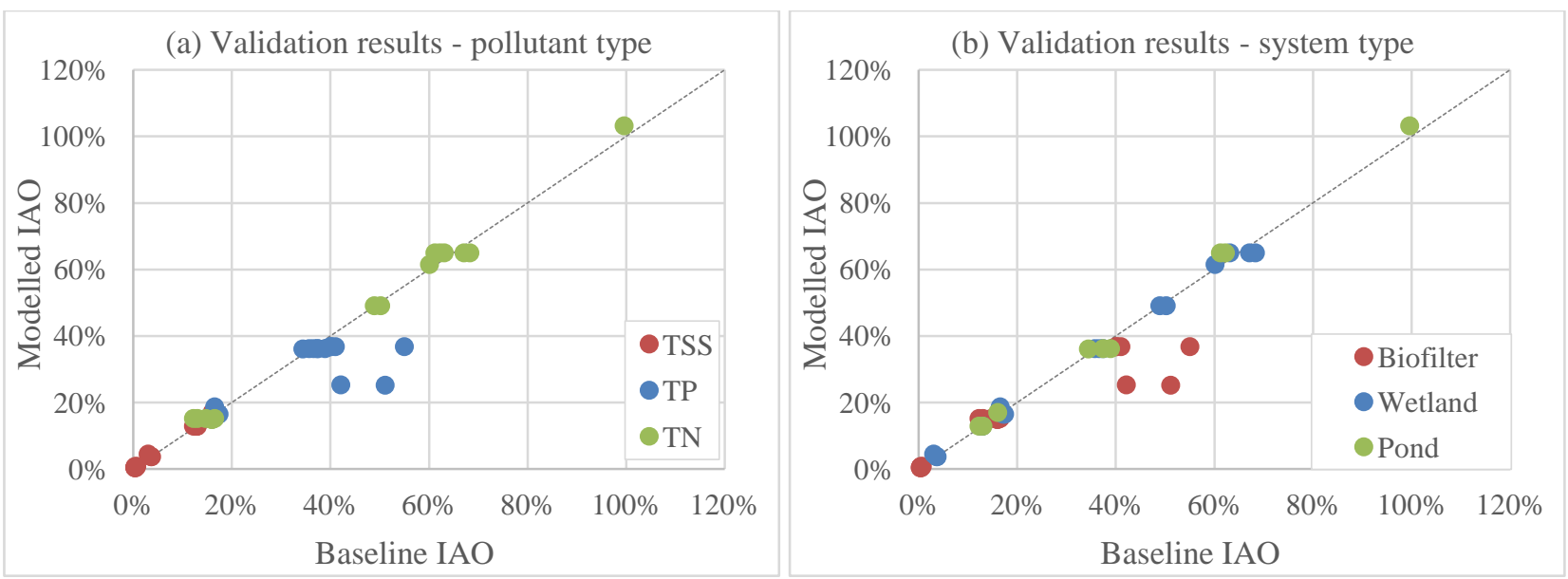

Figure 4 Results of validation of empirical relationships - baseline against modelled IAO values.

Each dot represents one validation scenario in Table 4, with different colours indicating (a) different type of pollutants, and (b) different types of systems. 

Electronic Supplementary Material (for online publication only)
Click here to download Electronic Supplementary Material (for c Click here to download Electronic Supplementary Material (for online publication only): SWH Benefits Paper_supplementary doc online (1) (1) (1) (1) . . . . . . . . . . . . . . . . . . . . . . . 